\title{
Intelligent PV Power Smoothing Control Using Probabilistic Fuzzy Neural Network with Asymmetric Membership Function
}

\author{
Faa-Jeng Lin, Su-Ying Lu, Jo-Yu Chao, and Jin-Kuan Chang \\ Department of Electrical Engineering, National Central University, Chungli 320, Taiwan \\ Correspondence should be addressed to Faa-Jeng Lin; linfj@ee.ncu.edu.tw
}

Received 26 May 2017; Accepted 8 August 2017; Published 14 November 2017

Academic Editor: Francesco Riganti Fulginei

Copyright ( 2017 Faa-Jeng Lin et al. This is an open access article distributed under the Creative Commons Attribution License, which permits unrestricted use, distribution, and reproduction in any medium, provided the original work is properly cited.

\begin{abstract}
An intelligent PV power smoothing control using probabilistic fuzzy neural network with asymmetric membership function (PFNN-AMF) is proposed in this study. First, a photovoltaic (PV) power plant with a battery energy storage system (BESS) is introduced. The BESS consisted of a bidirectional DC/AC 3-phase inverter and LiFePO4 batteries. Then, the difference of the actual PV power and smoothed power is supplied by the BESS. Moreover, the network structure of the PFNN-AMF and its online learning algorithms are described in detail. Furthermore, the three-phase output currents of the PV power plant are converted to the $d q$-axis current components. The resulted $q$-axis current is the input of the PFNN-AMF power smoothing control, and the output is a smoothing PV power curve to achieve the effect of PV power smoothing. Comparing to the other smoothing methods, a minimum energy capacity of the BESS with a small fluctuation of the grid power can be achieved by the PV power smoothing control using PFNN-AMF. In addition, a personal computer- (PC-) based PV power plant emulator and BESS are built for the experimentation. From the experimental results of various irradiance variation conditions, the effectiveness of the proposed intelligent PV power smoothing control can be verified.
\end{abstract}

\section{Introduction}

Since the environmental pollution problems of the world are deteriorated in recent years, developing clean energy sources and protecting the environment become the major issues of the modern world. Thus, the development and application of clean renewable energy sources, such as solar, wind, tides, fuel cell, and geothermal, are getting more and more worldwide attention. Among these renewable energy sources, solar power will gradually be dominant due to its availability and reliability. Owing to the price of the photovoltaic (PV) system declines of around $75 \%$ in less than 10 years has made the solar power more cost competitive in various countries and market segments; the cumulative installed capacity of the PV in the world has been reached to $178 \mathrm{GW}$ in the end of 2014 [1]. European Photovoltaic Industry Association (EPIA) predicts that the worldwide total installed capacity of the PV system in 2019 could reach between 396 and $540 \mathrm{GW}$ with the highest probability scenario being around $450 \mathrm{GW}$. Meanwhile, the government of Taiwan has decided to raise the official PV installation target from $13 \mathrm{GW}$ to
$20 \mathrm{GW}$ in 2025. In other words, the global cumulative PV capacity will have explosive growth in the next decade. Furthermore, the renewable energy source- (RES-) based distributed energy sources are normally connected to the grid using power electronics. Therefore, the development of a grid-connected PV system including DC/DC converter and $\mathrm{AC} / \mathrm{DC}$ inverter considering the ancillary service of power quality is important for solving the issues of environmental protection [2].

The intermittent nature of the output power from RESs becomes a serious concern for the stability of the grid particularly with increasing RES penetration and a high percentage of instantaneous demand being supplied by RESs. In Germany, $80 \%$ of instantaneous demand was supplied by RESs on Aug. 23, 2015. Therefore, significant operating reserves are required to meet the demand in case of a sudden decrease in the output of RESs, thus causing an increase in the operational cost of the power system [3]. Moreover, additional regulations and standards are expected to be imposed on large PV power plants owing to their potential adverse impacts on reliability and stability of the power system. A 
possible solution for regulating the intermittent output power of a PV power plant is to integrate a battery energy storage system (BESS) [4]. The BESS can provide flexible energy management solutions that can improve the power quality of renewable-energy power generation systems. Several control strategies and configurations for hybrid BESSs, such as combining the BESS with superconducting magnetic energy system, flywheel energy system, and energy capacitor system, have been proposed [5]. The BESSs have a response time in the range of milliseconds and are able to compensate in real time the high intermittency of the RESs by operating the BESSs in charging/discharging mode in order to keep the output power ramp rate of the power plant inside admissible values [6]. In Lin et al. [7], an intelligent wind power smoothing control using recurrent fuzzy neural network was developed. The difference of the actual wind power and smoothed power is supplied by the BESS. On the other hand, the state of charge (SOC) of a battery, which is used to describe its remaining capacity, is a very important control parameter for the battery usage. As the SOC is an important parameter, accurate estimation of the SOC can protect battery, prevent over discharge, improve the battery life, and facilitate the development of control strategies to save energy [8]. There are many methods to estimate the SOC of a battery including inverse mapping using the SOC-to-open circuit voltage characterization curves, Coulomb counting, impedance measurements, and algorithms using extended Kalman filter and particle filter $[9,10]$.

Since the neural networks possess the characteristics of fault tolerance, parallelism, and online learning, many researches of neural network modeling and control for renewable energy applications have been proposed [11-13]. In Liu et al. [11], a complex-valued recurrent neural network was proposed to predict the total output of the wind power plant based on historical data of wind speed and wind direction. Moreover, an improved differential evolution algorithm-based Elman neural network controller was proposed to control a squirrel-cage induction generator system for grid-connected wind power applications [12]. In Urias et al. [13], a prediction model that utilizes a layer recurrent neural network technique for estimating the wind power output of the turbine was proposed based on a multilayer neural network with back propagation training. In addition, a fuzzy neural network (FNN) is capable of fuzzy reasoning in handling uncertain information and artificial neural networks for learning from processes. Thus, there has been much research focused on using FNNs to represent complex plants and construct advanced controllers [14, 15] based on the back-propagation (BP) algorithm. Moreover, the probabilistic neural network (PNN) is a feedforward neural network, and its structure is the neural network implementation of Parzen nonparametric probability density function estimation and Bayes classification rule [16]. The PNNs can handle the uncertainties effectively and have been widely used in industrial applications [17-19]. According to the aforementioned advantages of FNNs and PNNs, the probabilistic FNN (PFNN), which combines the characteristics of FNN (degree of truth) and the characteristics of PNN (probability of truth), has been applied in some areas such as modeling and control problems [20, 21]. In addition, if the dimensions of the standard Gaussian are directly extended in asymmetric membership functions (AMFs), not only the learning capability of the networks can be upgraded but also the number of fuzzy rules can be optimized [22, 23].

A new PFNN-AMF is proposed in this study to develop an intelligent PV power smoothing control. The proposed PFNN-AMF is mainly developed based on PNN, fuzzy logic control, and AMF. Therefore, it possesses the superior modeling performance and adaptability of the PNN, the advantages of the fuzzy logic control to handle uncertain information and to approximate nonlinear systems, and the upgraded learning capability of the networks owing to the AMF. Moreover, actual PV power plant data from the PV power plant built in Australia is adopted for the PC-based PV power plant emulator in this study. Then, the threephase output currents of the PV power plant emulator are converted to the $d q$-axis current components. The resulted $q$-axis current represents the active power and also is the input of the PFNN-AMF power smoothing control. By using the excellent approximation and online training abilities of the PFNN-AMF with a grid power fluctuation limitation, a smoothed power with a very limited time delay can be obtained. Moreover, the difference of the actual PV power and smoothed power is supplied by the BESS. Therefore, using the PFNN-AMF power smoothing control, a minimum energy capacity of the BESS can be achieved with acceptable power quality of the grid. The grid active power fluctuation limits for per minute and per ten minutes are both set to be $10 \%$ of the rated power of the PV power plant in this study. This study is organized as follows: Section 2 illustrates the modeling of PV power plant and BESS. Section 3 describes the PFNN-AMF smoothing architecture including the network structure of the PFNN-AMF and its online learning algorithms. Section 4 and Section 5 provide some comparison of various smoothing methods and experimental results. Finally, some conclusions are given in Section 6.

\section{System Architecture}

2.1. Modeling of PV Power Plant. In general, a PV power plant comprises a large number of PV systems as shown in Figure 1. In each PV system, various PV modules are arranged in arrays and connected to the feeder through DC/DC and DC/AC converters with wireless communication module. The PV modules are constructed from a large number of solar cells in series-parallel configurations. The output of the PV power plant is then connected to the grid through a power transformer. In a PV power plant, since the PV modules are placed adjacent to each other, all the PV modules are assumed to have the same characteristics, solar radiation and operational and environmental factors that may affect the output of the power plant.

The maximum output power ratings of PV systems are provided by the manufacturers and usually are expressed in peak-watt $\left(W_{\mathrm{P}}\right)$. The current-voltage characteristics ( $I-V$ characteristics) under the standard test condition (the 


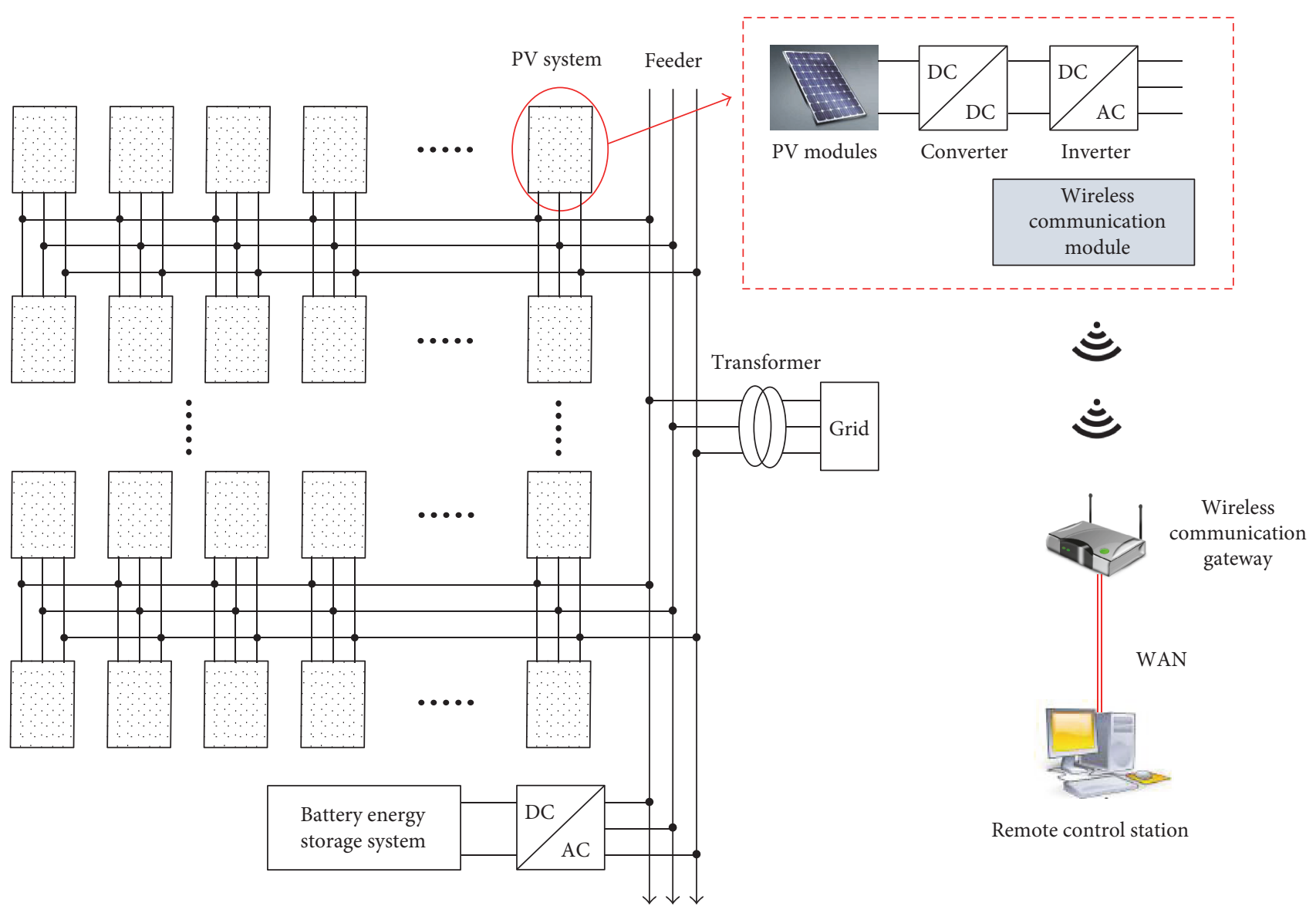

FIGURE 1: Schematic presentation of PV power plant with BESS.

radiation level of $1 \mathrm{~kW} / \mathrm{m}^{2}$ at a temperature of $25^{\circ} \mathrm{C}$ ) can be calculated using the following equations [24]:

$$
\begin{aligned}
I & =r\left[I_{\mathrm{sc}}+K_{I}\left(T_{\mathrm{c}}-25\right)\right], \\
V & =V_{\mathrm{oc}}-K_{V} T_{\mathrm{c}},
\end{aligned}
$$

where $r$ is the radiation level; $I_{\mathrm{sc}}$ is the short circuit current; $K_{I}$ is the short circuit current temperature coefficient in $A /{ }^{\circ} \mathrm{C} ; V_{\text {oc }}$ is the open circuit voltage; $K_{V}$ is the open circuit voltage temperature coefficient in $V /{ }^{\circ} \mathrm{C}$; and $T_{c}$ is the cell temperature in ${ }^{\circ} \mathrm{C}$ which can be expressed as follows [24]:

$$
T_{\mathrm{c}}=T_{\mathrm{a}}+r\left(\frac{T_{\mathrm{no}}-20}{0.8}\right)
$$

where $T_{\mathrm{a}}$ is the ambient temperature and $T_{\text {no }}$ is the nominal operating temperature of the cell. The ideal output power $P^{*}$ of a PV power plant for a given radiation level, ambient temperature, and the current-voltage characteristics can be calculated using the following relationships:

$$
P^{*}=n \mathrm{FF} I V \text {, }
$$

where $n$ is the total number of PV modules and FF is the fill factor, which depends on the module characteristics [25]. However, considering the energy losses due to array temperature, incomplete utilization of the irradiation, converter losses, and system component inefficiency, the actual output power $P_{\mathrm{pv}}$ of a $\mathrm{PV}$ power plant can be expressed as follows:

$$
P_{\mathrm{pv}}=n \mathrm{FF} I V \mathrm{PR},
$$

where PR is the performance ratio defined in IEC61724 [26].

2.2. Modeling of Battery Energy Storage System. In this study, a BESS with one-stage circuit architecture is developed as a PV power smoothing control. The BESS and the PV power plant emulator are also connected to the grid as shown in Figure 2. The bidirectional DC/AC three-phase inverter is responsible for the two-way power transmission between the battery terminal and the PV power plant emulator. It is responsible for supplying the power difference of the actual PV power and smoothed power. Moreover, in Figure 2, $i_{g a}$, $i_{g b}$, and $i_{g c}$ are the three-phase output currents of the PV power plant emulator; $i_{o a}, i_{o b}$, and $i_{o c}$ are the three-phase output currents of the DC/AC inverter; $v_{\text {bat }}$ and $i_{\text {bat }}$ are the DC bus voltage and converter input current of the DC/DC converter; $v_{a}^{*}, v_{b}^{*}$, and $v_{c}^{*}$ are the PWM voltage commands of the DC/AC inverter; $v_{a}, v_{b}$, and $v_{c}$ are the three-phase voltages of the grid; $i_{a}, i_{b}$, and $i_{c}$ are the three-phase currents of the grid; $v_{q}^{*}$ and $v_{d}^{*}$ are the $d q$-axis PWM voltage commands of 


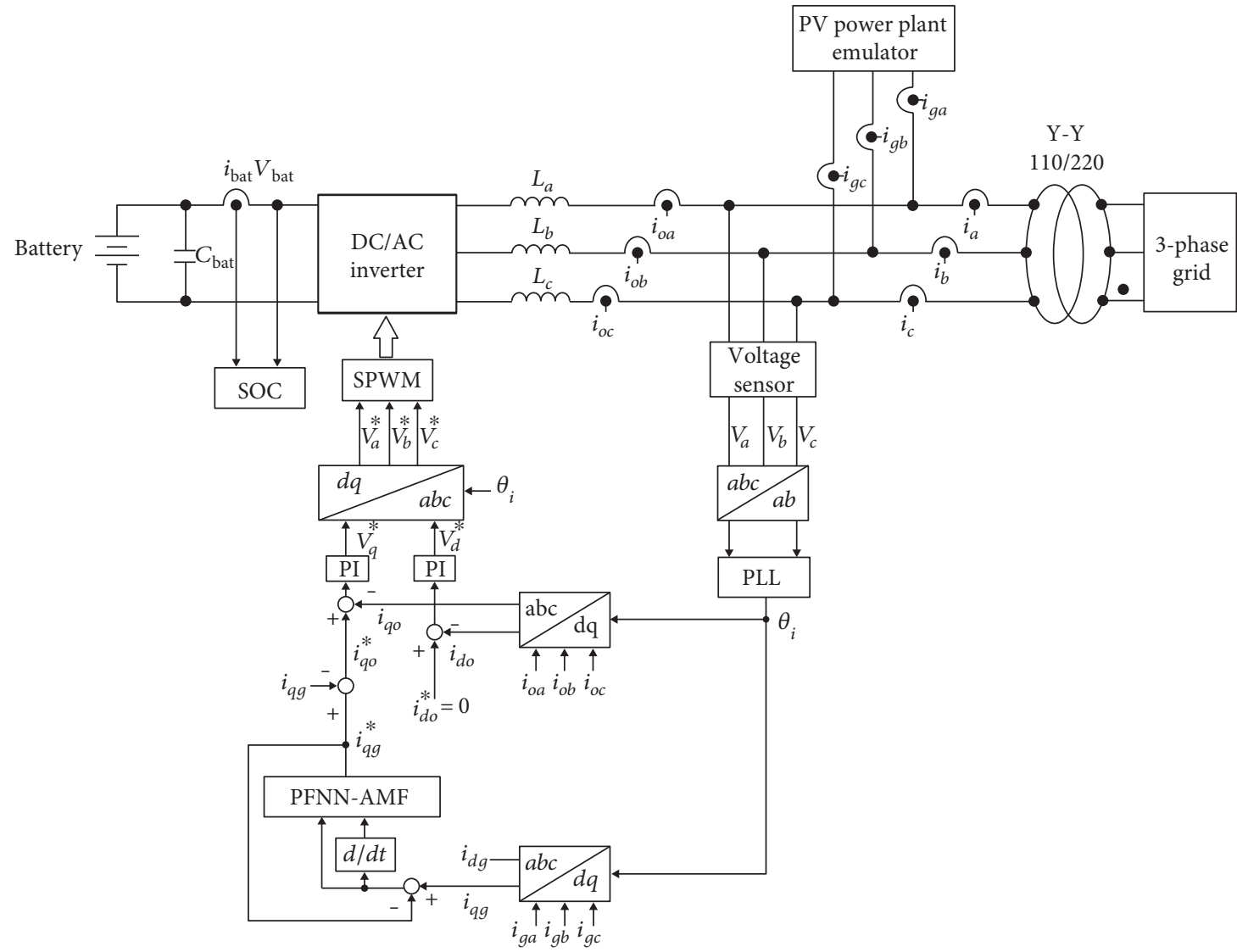

FIgURE 2: BESS with intelligent PV power plant smoothing control.

the DC/AC inverter; $i_{q g}^{*}$ and $i_{q g}$ are the $q$-axis output current command and $q$-axis output current of the PV power plant emulator, that is, the active power component; $i_{d g}$ is the $d$-axis output current of the PV power plant emulator, that is, the reactive power component; $i_{d o}^{*}, i_{q o}^{*}, i_{d o}$, and $i_{q o}$ are the $d q$-axis output current commands and $d q$-axis output currents of the DC/AC inverter; and $\theta_{i}$ is the synchronous angle obtained from phase-lock-loop (PLL) block. The axis conversions between the $i_{o a}, i_{o b}, i_{o a}$, and $i_{d o}, i_{q o}$ and $v_{q}^{*}, v_{d}^{*}$, and $v_{a}^{*}, v_{b}^{*}, v_{c}^{*}$ are shown in the following:

$$
\begin{aligned}
& {\left[\begin{array}{l}
i_{d o} \\
i_{q o}
\end{array}\right]=\frac{2}{3}\left[\begin{array}{ccc}
\cos \theta_{i} & \cos \left(\theta_{i}-\frac{2 \pi}{3}\right) & \cos \left(\theta_{i}+\frac{2 \pi}{3}\right) \\
\sin \theta_{i} & \sin \left(\theta_{i}-\frac{2 \pi}{3}\right) & \sin \left(\theta_{i}+\frac{2 \pi}{3}\right)
\end{array}\right]\left[\begin{array}{c}
i_{o a} \\
i_{o b} \\
i_{o c}
\end{array}\right],} \\
& {\left[\begin{array}{c}
v_{a}^{*} \\
v_{b}^{*} \\
v_{c}^{*}
\end{array}\right]=\left[\begin{array}{cc}
\cos \theta_{i} & \sin \theta_{i} \\
\cos \left(\theta_{i}-\frac{2 \pi}{3}\right) & \sin \left(\theta_{i}-\frac{2 \pi}{3}\right) \\
\cos \left(\theta_{i}+\frac{2 \pi}{3}\right) & \sin \left(\theta_{i}+\frac{2 \pi}{3}\right)
\end{array}\right]\left[\begin{array}{c}
v_{q}^{*} \\
v_{d}^{*}
\end{array}\right]}
\end{aligned}
$$

For the three-phase inverter of the BESS, it is controlled by the $d q$-axis current control. The $d$-axis current control is responsible for the reactive power control by using the reactive power current command $i_{d o}^{*}$ and is set to be zero. The $q$-axis current control is responsible for the active power control by using the active power current command $i_{q o}^{*}$, which is the difference between the output of the PFNN-AMF $i_{q g}^{*}$ and the active power component of the PV power $i_{q g}$. When the current command $i_{q o}^{*}$ is positive, the circuit operates in inverter mode, and the battery is discharged. Conversely, when the current command $i_{q o}^{*}$ is negative, the circuit operates in rectifier mode, and the battery is charged. The individual difference between the current command $i_{d o}^{*}$ and $i_{q o}^{*}$ and the current $i_{d o}$ and $i_{q o}$ are regulated via two proportional-integral (PI) controllers to generate the respective $d q$-axis voltage command $v_{q}^{*}$ and $v_{d}^{*}$. Then $v_{q}^{*}$ and $v_{d}^{*}$ are converted to voltage command $v_{a}^{*}, v_{b}^{*}$, and $v_{c}^{*}$ in $a b c$-axis for sinusoidal PWM (SPWM) by using the synchronous angle $\theta_{i}$.

\section{PFNN-AMF PV Power Smoothing Control}

A PFNN-AMF is proposed in this study for the intelligent PV power smoothing control owing to its excellent approximation and online training abilities. Using the PFNN-AMF power smoothing control and considering the constraint of grid power fluctuation rate, a smoothed 


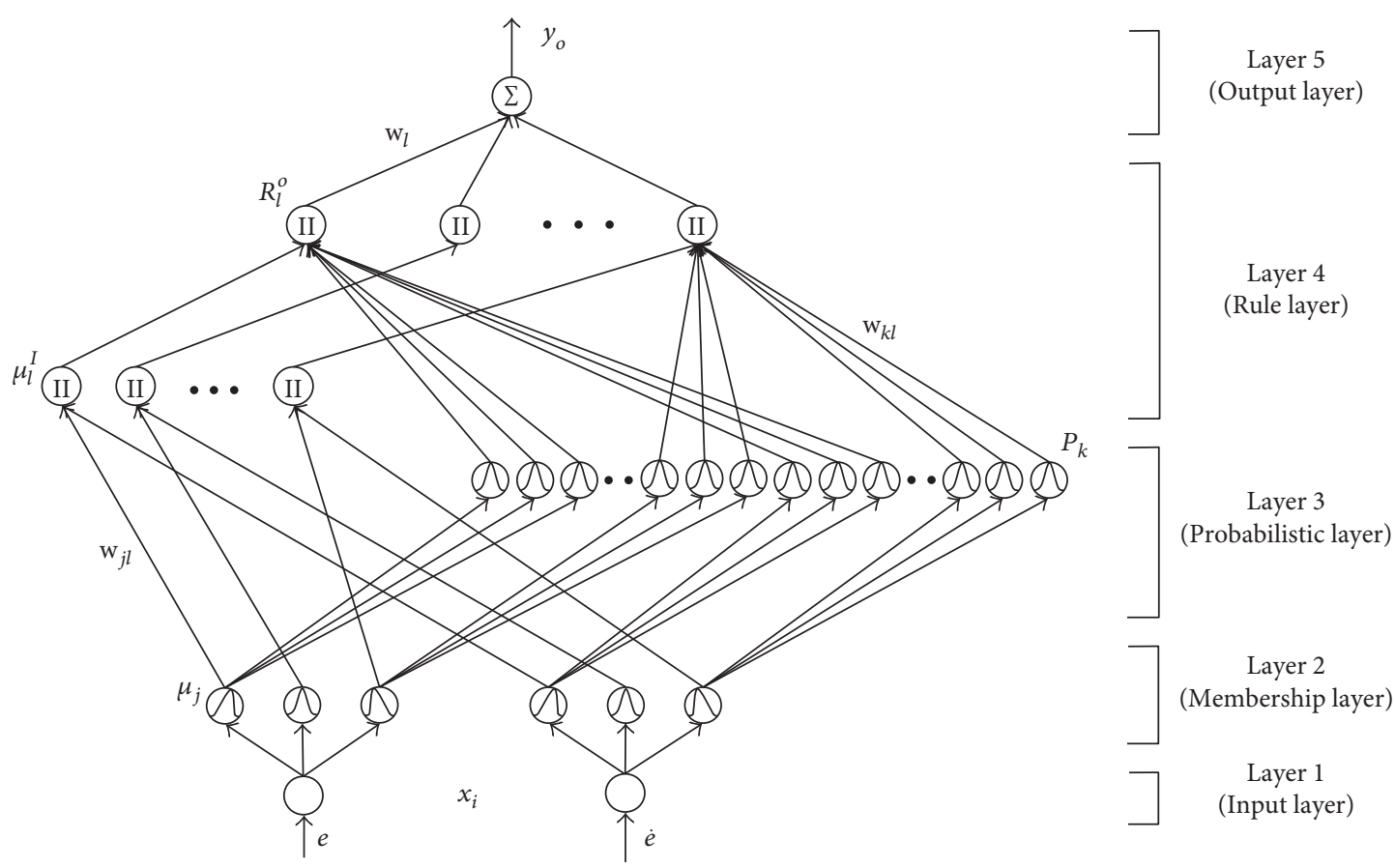

(a) Structure of PFNN-AMF

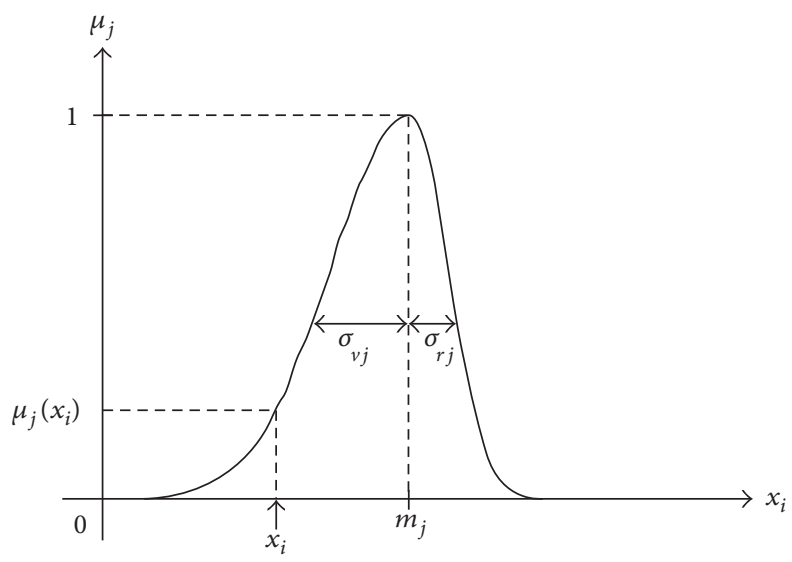

(b) Asymmetric Gaussian function in membership layer of

PFNN-AMF

FIgURE 3: PFNN with asymmetric membership function.

power with a very limited time delay can be obtained. Since the difference of the actual PV power and smoothed power is supplied by the BESS, the minimum capacity of the BESS can be achieved with acceptable power quality of the grid. The network structure of the PFNNAMF and its online learning algorithms are introduced in this section.

3.1. PFNN-AMF. A five-layer PFNN-AMF, which includes the input layer (layer 1), the membership layer (layer 2), the probabilistic layer (layer 3), the rule layer (layer 4), and the output layer (layer 5) with two inputs and one output, is shown in Figure 3(a). Moreover, the signal propagation and the basic function of each layer are introduced in the following.
3.1.1. Layer 1 (Input Layer). In the input layer, the node input and the node output are represented as:

$$
\begin{aligned}
\operatorname{net}_{i}(N) & =x_{i}, \\
y_{i}(N) & =f_{i}\left(\operatorname{net}_{i}(N)\right)=\operatorname{net}_{i}(N), \quad i=1,2,
\end{aligned}
$$

where $x_{i}$ represents the $i$ th input to the input layer and $N$ represents the $N$ th iteration. In this study, the input variables are $e_{1}(N)=e=i_{q g}^{*}-i_{q g}$ and $e_{2}(N)=\dot{e}$, which are the tracking error and its derivative, respectively.

3.1.2. Layer 2 (Membership Layer). In the membership layer, each node utilizes an asymmetric Gaussian function to realize the fuzzification operation in the PFNN-AMF as shown in Figure 3(b). By using the asymmetric membership 
functions (AMFs), the learning capability of the networks can be upgraded and the number of fuzzy rules can be optimized by extending the dimensions of the standard Gaussian function $[22,23]$. The node input and output of this layer are presented as

$$
\begin{gathered}
\operatorname{net}_{j}(N)= \begin{cases}-\frac{\left(y_{i}(N)-m_{j}(N)\right)^{2}}{\left(\sigma_{v j}(N)\right)^{2}}, & -\infty<y_{i}(N) \leq m_{j} \\
-\frac{\left(y_{i}(N)-m_{j}(N)\right)^{2}}{\left(\sigma_{r j}(N)\right)^{2}}, & m_{j}<y_{i}(N) \leq \infty,\end{cases} \\
\mu_{j}(N)=f_{j}\left(\operatorname{net}_{j}(N)\right)=\exp \left(\operatorname{net}_{j}(N)\right), \quad j=1,2, \ldots, 6,
\end{gathered}
$$

where $\mu_{j}(N)$ is the layer 2 node output; $m_{j}$ is the mean of the asymmetric Gaussian function in the $j$ th term associated with the $i$ th input variable; and $\sigma_{v j}$ and $\sigma_{r j}$ are the left-hand-side and right-hand-side standard deviations of the asymmetric Gaussian function in the $j$ th term associated with the $i$ th input variable, respectively.

3.1.3. Layer 3 (Probabilistic Layer). In the probabilistic layer, the Gaussian function is adopted and each node represents a Gaussian function. The general form for these nodes of this layer can be expressed as

$$
\begin{aligned}
\operatorname{net}_{k}(N) & =-\frac{\left(\mu_{j}(N)-m_{k}\right)^{2}}{\left(\sigma_{k}\right)^{2}}, \\
P_{k}(N) & =f_{k}\left(\operatorname{net}_{k}(N)\right)=\exp \left(\operatorname{net}_{k}(N)\right), \quad k=1,2, \ldots, 18,
\end{aligned}
$$

where $P_{k}(N)$ is the layer 3 output and $m_{k}$ and $\sigma_{k}$ are the mean and standard deviation of the Gaussian function, respectively.

3.1.4. Layer 4 (Rule Layer). In the rule layer, each node corresponds to a rule in the knowledge base. By using the Mamdani inference, the node itself performs the $t$-norm operation (product operation) to obtain the inference set according to the rules as shown in (9). The probabilistic information is processed using the Bayes' theorem in consideration of the group of fuzzy grade being independent variables as shown in (10). Moreover, the input of the output node of this layer shown in (11) is the production of $\mu_{l}^{I}(N)$ and $P_{l}^{I}(N)$, which are defined as follows:

$$
\begin{aligned}
& \mu_{l}^{I}(N)=\prod_{j} w_{j l} \mu_{j}(N), \\
& P_{l}^{I}(N)=\prod_{k} w_{k l} P_{k}(N),
\end{aligned}
$$

where $w_{j l}$ is the connective weight between the membership layer and the rule layer which is set to be 1 and $w_{k l}$ is the connective weight between the probabilistic layer and the rule layer which is also set to be 1 . In addition, the input and output of the output node of this layer are represented as

$$
\begin{aligned}
\operatorname{net}_{l}(N) & =\mu_{l}^{I}(N) P_{l}^{I}(N), \\
R_{l}^{O}(N) & =f_{l}\left(\operatorname{net}_{l}(N)\right)=\operatorname{net}_{l}(N), \quad l=1,2, \ldots, 9,
\end{aligned}
$$

where $R_{l}^{O}(N)$ is the $l$ th node output of the rule layer.

3.1.5. Layer 5 (Output Layer). In the output layer, the single node $o$ in this layer is labeled with $\sum$, which computes the overall output as the summation of all input signals. The node output is represented as

$$
\begin{aligned}
\operatorname{net}_{o}(N) & =\sum_{l} w_{l}(N) R_{l}^{O}(N), \\
y_{o}(N) & =f_{o}\left(\operatorname{net}_{o}(N)\right)=\operatorname{net}_{o}(N), \quad o=1,
\end{aligned}
$$

where the connecting weight $w_{l}(N)$ is the output action strength of the oth output associated with the lth rule, $R_{l}^{O}(N)$ represents the $l$ th input to the node of layer 5 , and $y_{o}(N)$ equals the control current $i_{q g}$.

3.2. Online Parameter Training. The central part of the learning algorithm for the PFNN-AMF concerns how to recursively obtain a gradient vector in which each element in the learning algorithm is defined as the derivative of an energy function with respect to a parameter of the network by using the back-propagation (BP) learning rule. To describe the online learning algorithm of the PFNN-AMF using the supervised gradient decent method, the energy function $E(N)$ is defined as

$$
E(N)=\frac{1}{2}\left(i_{q g}^{*}-i_{q g}\right)^{2}=\frac{1}{2} e^{2}
$$

where $e=i_{q g}^{*}-i_{q g}$. Then, the learning algorithm is described as follows.

3.2.1. Layer 5. The error term to be propagated is given by

$$
\delta_{o}^{5}=-\frac{\partial E}{\partial y_{o}(N)}=-\frac{\partial E}{\partial i_{q g}} \frac{\partial i_{q g}}{\partial y_{o}(N)} .
$$

The weight is updated by the amount:

$$
\Delta w_{l}=-\eta_{1} \frac{\partial E}{\partial w_{l}}=-\eta_{1} \frac{\partial E}{\partial y_{o}(N)} \frac{\partial y_{o}(N)}{\partial w_{l}}=\eta_{1} \delta_{o}^{5} R_{l}^{O},
$$

where the factor $\eta_{1}$ is the learning rate. The connective weight $w_{l}$ is updated according to the following equation:

$$
w_{l}(N+1)=w_{l}(N)+\Delta w_{l}
$$

3.2.2. Layer 4. In this layer, the error terms to be propagated are given by

$$
\delta_{l}=-\frac{\partial E}{\partial R_{l}^{O}(N)}=-\frac{\partial E}{\partial y_{o}(N)} \frac{\partial y_{o}(N)}{\partial R_{l}^{O}(N)}=\delta_{o}^{5} w_{l} .
$$

3.2.3. Layer 2. The error terms to be propagated are given by

$$
\delta_{j}=-\frac{\partial E}{\partial \mu_{j}(N)}=-\frac{\partial E}{\partial y_{o}(N)} \frac{\partial y_{o}(N)}{\partial R_{l}^{O}(N)} \frac{\partial R_{l}^{O}(N)}{\partial \mu_{l}^{I}(N)} \frac{\partial \mu_{l}^{I}(N)}{\partial \mu_{j}(N)}=\sum_{l} \delta_{l} P_{l}^{I} .
$$


Applying the chain rule, the update law of mean of the asymmetric Gaussian function is

$$
\begin{aligned}
\Delta m_{j}= & -\eta_{2} \frac{\partial E}{\partial m_{j}}=-\eta_{2} \frac{\partial E}{\partial y_{o}(N)} \frac{\partial y_{o}(N)}{\partial R_{l}^{O}(N)} \frac{\partial R_{l}^{O}(N)}{\partial \mu_{l}^{I}(N)} \frac{\partial \mu_{l}^{I}(N)}{\partial \mu_{j}(N)} \frac{\partial \mu_{j}(N)}{\partial m_{j}} \\
& = \begin{cases}2 \eta_{2} \delta_{j} \frac{y_{i}(N)-m_{j}(N)}{\left(\sigma_{v j}(N)\right)^{2}}, & -\infty<y_{i}(N) \leq m_{j} \\
2 \eta_{2} \delta_{j} \frac{y_{i}(N)-m_{j}(N)}{\left(\sigma_{r j}(N)\right)^{2}}, & m_{j}<y_{i}(N) \leq \infty .\end{cases}
\end{aligned}
$$

Moreover, the update rules of $\sigma_{v j}$ and $\sigma_{r j}$ are derived as follows:

$$
\begin{aligned}
\Delta \sigma_{v j} & =-\eta_{3} \frac{\partial E}{\partial \sigma_{v j}}=-\eta_{3} \frac{\partial E}{\partial y_{o}(N)} \frac{\partial y_{o}(N)}{\partial R_{l}^{O}(N)} \frac{\partial R_{l}^{O}(N)}{\partial \mu_{l}^{I}(N)} \frac{\partial \mu_{l}^{I}(N)}{\partial \mu_{j}(N)} \frac{\partial \mu_{j}(N)}{\partial \sigma_{v j}} \\
& =2 \eta_{3} \delta_{j} \frac{\left(y_{i}(N)-m_{j}(N)\right)^{2}}{\left(\sigma_{v j}(N)\right)^{3}}, \\
\Delta \sigma_{r j} & =-\eta_{4} \frac{\partial E}{\partial \sigma_{r j}}=-\eta_{4} \frac{\partial E}{\partial y_{o}(N)} \frac{\partial y_{o}(N)}{\partial R_{l}^{O}(N)} \frac{\partial R_{l}^{O}(N)}{\partial \mu_{l}^{I}(N)} \frac{\partial \mu_{l}^{I}(N)}{\partial \mu_{j}(N)} \frac{\partial \mu_{j}(N)}{\partial \sigma_{r j}} \\
& =2 \eta_{4} \delta_{j} \frac{\left(y_{i}(N)-m_{j}(N)\right)^{2}}{\left(\sigma_{r j}(N)\right)^{3}}
\end{aligned}
$$

where the factors $\eta_{2}, \eta_{3}$, and $\eta_{4}$ are the learning rates. The mean and left-hand-side and right-hand-side standard deviations of the asymmetric membership functions are updated according to the following equations:

$$
\begin{gathered}
m_{j}(N+1)=m_{j}(N)+\Delta m_{j}, \\
\sigma_{v j}(N+1)=\sigma_{v j}(N)+\Delta \sigma_{v j}, \\
\sigma_{r j}(N+1)=\sigma_{r j}(N)+\Delta \sigma_{r j} .
\end{gathered}
$$

In order to reduce the computation load, in layer 3 , the mean $m_{k}$ and the standard deviation $\sigma_{k}$ are constants where $m_{k}$ is set to be 0.4 for $k=1,4,7,10,13$, and 16 ; to be 0.5 for $k=2,5,8,11,14$, and 17 ; and to be 0.6 for $k=3,6,9$, 12,15 , and $18 ; \sigma_{k}$ is set to be 1 . Furthermore, the exact calculation of the Jacobian of the system, $\partial i_{q g} / \partial y_{o}(N)$, is difficult to be determined due to the unknown dynamics of the BESS. To overcome this problem, a delta adaptation law is adopted as follows [27]:

$$
\delta_{o}^{5} \cong\left(i_{q g}^{*}-i_{q g}\right)+\left(\dot{i}_{q g}^{*}-\dot{i}_{q g}\right)=e+\dot{e},
$$

where $\dot{i}_{q g}^{*}$ and $\dot{i}_{q g}$ represent the first derivatives of the $q$-axis current command and $q$-axis current, respectively. In addition, the values of the learning rates $\eta_{1}, \eta_{2}, \eta_{3}, \eta_{4}$ are usually set to be between 0 and 1 . In general, larger values of the learning rates $\eta_{1}, \eta_{2}, \eta_{3}, \eta_{4}$ could result in divergence of the control responses. On the other hand, smaller values of the learning rates $\eta_{1}, \eta_{2}, \eta_{3}, \eta_{4}$ could result in slow convergence of the control responses. Thus, in this study, the values of the learning rates $\eta_{1}, \eta_{2}, \eta_{3}, \eta_{4}$ are set to be $0.513,0.372,0.46$, and 0.284 by empirical rules.

3.3. PFNN-AMF Power Smoothing Control. In the power smoothing control, first, the output three-phase currents of the PV power plant emulator are converted to $d q$-axis current components. The resulted $q$-axis current $i_{q g}$ represents the active current component of the PV power plant emulator. The difference between the output of the PFNN-AMF $i_{q g}^{*}$ and $i_{q g}$, that is, $e(t)$ and its derivative $\dot{e}(t)$ are the two inputs of the PFNN-AMF power smoothing control. After that, the output signal $i_{q g}^{*}$ is generated through the feedforward structure of the PFNN-AMF following the online learning parameters of the network. This cycle is repeated every $5 \mathrm{~ms}$. Since the learning process is to minimize the difference between $i_{q g}^{*}$ and $i_{q g}$, that is, $e(t)$, the curve of the output of PFNN-AMF $i_{q g}^{*}$ will be quite similar to the curve of $i_{q g}$ with limited time delay. On the other hand, though the PFNNAMF possesses excellent approximation ability, it is not perfect. Thus, the nonperfect $i_{q g}^{*}$ results in a more gentle PV power curve to achieve the effect of $\mathrm{PV}$ power smoothing. Therefore, the proposed PFNN-AMF PV power smoothing scheme not only can reduce the amount of battery capacity effectively but also takes the power quality of the grid into account.

\section{Comparison of Smoothing Methods}

The main objective of this research is to determine the necessary capacity of BESS for use in conjunction with a PV power plant that allows the output of the combined PV power plant and BESS to meet the connected grid requirements, that is, the fluctuation of injected power to the grid should be kept below some percentage of the rated power to maintain the grid power quality. To verify the effectiveness of the proposed power smoothing control strategy, an actual 12-hour PV power data from the PV power plant built at the University of Queensland, Australia, [28] is adopted. In Figures 4(a), 4(b), 4(c), 4(d), and 4(e), the PV power data is selected from 6 o'clock to 18 o'clock, and the comparison of smoothing methods include the average method, the moving average method, the low-pass filter method, the PFNN method proposed in [20], and the proposed PFNN-AMF method, where $P_{\mathrm{pv}}$ is the actual PV power and $P_{\text {out }}$ in the smoothed power. Moreover, $P_{\text {out }}$ can be calculated from $i_{q g}^{*}$. The required energy capacity and the required power capacity of the BESS could be described by the following equation:

$$
\begin{aligned}
& E_{\mathrm{BESS}}=\max \left\{\sum_{i=a}^{i=a+N}\left(\left|P_{\mathrm{pv}}\left(t_{i}\right)-P_{\text {out }}\left(t_{i}\right)\right|\right) \Delta t\right\}, \\
& P_{\mathrm{pv}}>P_{\text {out }} \text { or } P_{\text {out }}>P_{\mathrm{pv}}, \\
& P_{\mathrm{BESS}}=\max \left\{\left|P_{\mathrm{pv}}\left(t_{i}\right)-P_{\text {out }}\left(t_{i}\right)\right|\right\},
\end{aligned}
$$

where $a$ and $a+\mathrm{N}$ are the start and stop time of continues charging or discharging and $\Delta t$ is the sampling interval which is $1 \mathrm{~s}$. The resulted energy capacities and power 

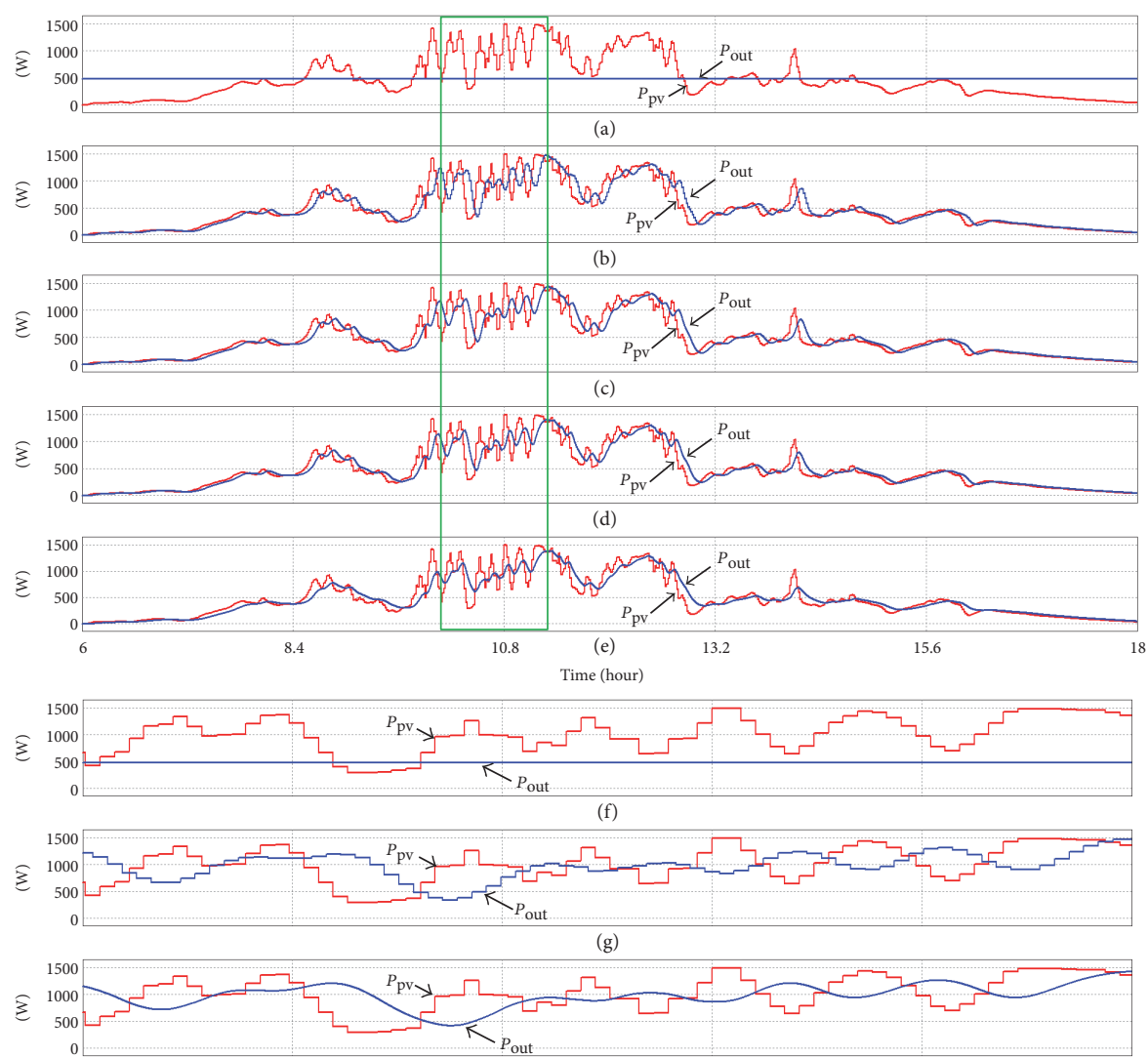

(h)

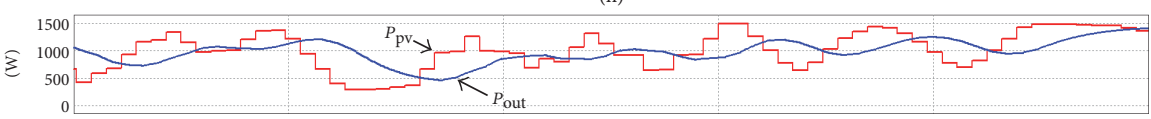

(i)
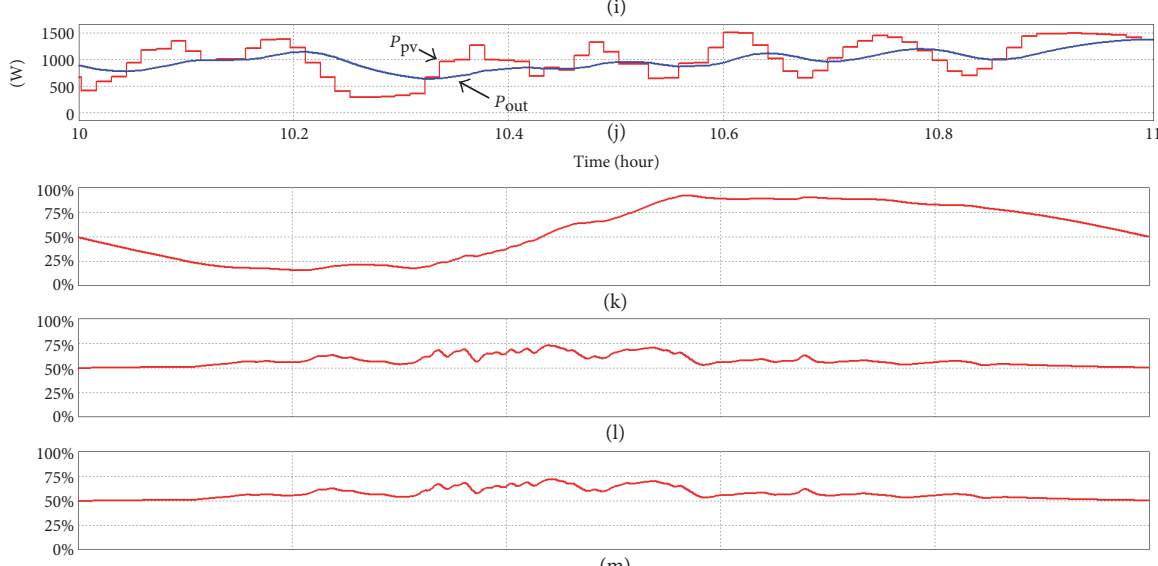

$(\mathrm{m})$

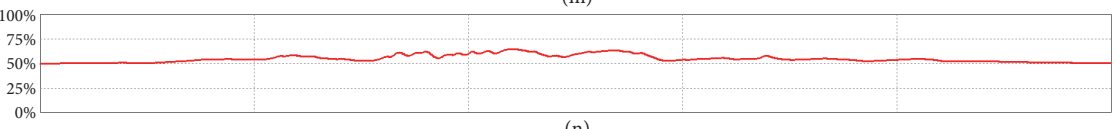

(n)

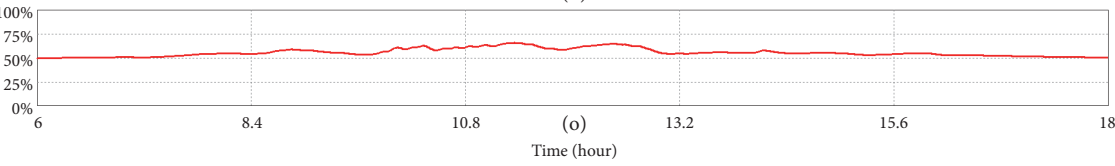

Figure 4: Comparison of smoothing methods: (a) average method; (b) moving average method; (c) low-pass filter method; (d) PFNN method; (e) PFNN-AMF method; (f) enlarged responses of average method; (g) enlarged responses of moving average method; (h) enlarged responses of low-pass filter method; (i) enlarged responses of PFNN method; (j) enlarged responses of PFNN-AMF method; (k) SOC of average method; (l) SOC of moving average method; (m) SOC of low-pass filter method; (n) SOC of PFNN method; (o) SOC of PFNN-AMF method. 
TABLE 1: Required energy capacity and power capacity of battery of various smoothing methods.

\begin{tabular}{lccccc}
\hline & Average & $\begin{array}{c}\text { Moving } \\
\text { average }\end{array}$ & LPF & PFNN & $\begin{array}{c}\text { PFNN- } \\
\text { AMF }\end{array}$ \\
\hline $\begin{array}{l}\text { Energy capacity, } \\
\text { kWh }\end{array}$ & 2.23 & 0.332 & 0.324 & 0.281 & 0.263 \\
$\begin{array}{l}\text { Power capacity, } \\
\text { kW }\end{array}$ & 1.018 & 0.834 & 0.788 & 0.685 & 0.643 \\
\hline
\end{tabular}

capacities using (24) and (25) of the various methods shown in Figures 4(a), 4(b), 4(c), 4(d), and 4(e) are shown in Table 1 where the average method requires the largest energy and power capacities of the battery and the proposed PFNNAMF method required the smallest energy and power capacities of the battery. Moreover, the green window highlighted from 10 o'clock to 11 o'clock in Figures 4(a), 4(b), 4(c), 4(d), and 4(e) is enlarged in Figures 4(f), 4(g), 4(h), 4(i), and $4(\mathrm{j})$. From the simulated results shown in Figures $4(\mathrm{f})$, $4(\mathrm{~g}), 4(\mathrm{~h}), 4(\mathrm{i})$, and $4(\mathrm{j})$, the time delay phenomena of the smoothed curves of the moving average and first-order low pass filter methods are very obvious. Only a smoothed power curve with limited time delay and with the minimum energy capacity of the BESS can both be obtained by the proposed intelligent smoothing method using PFNN-AMF. Furthermore, in this study, the state of charge (SOC) estimation using Coulomb counting method [10] is adopted for the management of the active power. In addition, in the energy management of the battery, the ordinary minimum and maximum SOC is $10 \%$ and $90 \%$, respectively. For the comparison of various smoothing methods and considering the allowed minimum SOC, a BESS consisting of $6 \mathrm{LiFePO} 4$ batteries with $40 \mathrm{~V} / 30 \mathrm{Ah}$ is adopted in this study. Additionally, the responses of the SOC for 12 hours of various smoothing methods are shown in Figures 4(k), 4(1), 4(m), 4(n), and 4(o) where the SOC of the average method reaches nearly its lowest limit $10 \%$. On the other hand, there still have plenty of capacities for all the other four methods especially the proposed PFNN-AMF method.

To further compare the smoothing performance of various smoothing methods for power quality, the standard deviation of the smoothed power is defined as follows:

$$
\sqrt{\frac{\sum_{i=1}^{h}\left(P_{\mathrm{pv}}\left(t_{i}\right)-P_{\mathrm{out}}\left(t_{i}\right)\right)^{2}}{h}}
$$

where $h$ is the total number of sampling of 12 hours. The standard deviations of smoothed power of various smoothing methods are shown in Table 2 where the PFNN-AMF method still has the smallest value. In addition, the grid active power fluctuation limits for per minute and per ten minutes are both set to be $10 \%$ of the rated power of the PV power plant in this study [29]. The fluctuation percentages of the injected power using the average method, the moving average method, the low-pass filter method, the PFNN method, and the PFNN-AMF method are shown in Figure 5 where $1 \mathrm{~min}$ average window is shown in Figures 5(a), 5(b), 5(c), $5(\mathrm{~d})$, and 5(e) and $10 \mathrm{~min}$ average window is shown in
TABLE 2: Standard deviation of smoothed power of various smoothing methods.

\begin{tabular}{cccccc}
\hline & Average & Moving average & LPF & PFNN & PFNN-AMF \\
\hline $\mathrm{kW}$ & 0.378 & 0.17 & 0.163 & 0.139 & 0.133 \\
\hline
\end{tabular}

Figures 5(f), 5(g), 5(h), 5(i), and 5(j). Only the PFNN and the proposed PFNN-AMF methods satisfy the active power fluctuation $10 \%$ limit for both per minute and per ten minutes. In addition, from the simulation results shown in Figure 5, the performance of the proposed PFNN-AMF method is better than the PFNN method. Therefore, the power quality of the proposed PFNN-AMF power smoothing control can also be guaranteed.

\section{Experimental Set-Up and Experimentation}

5.1. Experimental Set-Up. The block diagram of the PC-based BESS and a PC-based PV power plant emulator is shown in Figure 6 where the $q$-axis current control is responsible for the active power control of the BESS by using the active power current command $i_{q o}^{*}$, which is the difference between the output of the PFNN-AMF $i_{q g}^{*}$ and the active power component of the PV power $i_{q g}$. The $d$-axis current control is responsible for the reactive power control by using the reactive power current command $i_{d o}^{*}$ and is set to be zero. Moreover, the photos of the PC-based PV power plant emulator and the PC-based BESS are shown in Figure 7. For the $1.5 \mathrm{~kW}$ PC-based PV power plant emulator, a currentcontrolled PWM inverter is adopted, and the emulation of PV power plant is realized via Simulink. For the PC-based BESS, the capacity of the bidirectional DC/AC three-phase inverter is $1.5 \mathrm{~kW}$ and the DC bus voltage is $240 \mathrm{~V}$. Furthermore, three intervals are selected as three different cases from the 12-hour PV power data provided by the St. Lucia Campus in Queensland University, and each case with $720 \mathrm{~s}$ is built for implementation. These cases are based on the variation of the irradiance $700 \mathrm{~W} / \mathrm{m}^{2}-900 \mathrm{~W} / \mathrm{m}^{2}-1000 \mathrm{~W} / \mathrm{m}^{2}-900 \mathrm{~W} /$ $\mathrm{m}^{2}, \quad 900 \mathrm{~W} / \mathrm{m}^{2}-1000 \mathrm{~W} / \mathrm{m}^{2}-900 \mathrm{~W} / \mathrm{m}^{2}-800 \mathrm{~W} / \mathrm{m}^{2}$, and $700 \mathrm{~W} / \mathrm{m}^{2}-800 \mathrm{~W} / \mathrm{m}^{2}-700 \mathrm{~W} / \mathrm{m}^{2}-900 \mathrm{~W} / \mathrm{m}^{2}-1000 \mathrm{~W} / \mathrm{m}^{2}$.

In addition, to show the effectiveness of the PV smoothing control with small number of neurons, only 6 and 9 neurons are adopted at the membership and rule layers in the proposed PFNN-AMF by empirical rules in order to achieve fast dynamic responses of the smoothing control and to reduce the execution time simultaneously.

5.2. Experimentation. The experimental results using the proposed PFNN-AMF smoothing method at the PV irradiance variation condition $700 \mathrm{~W} / \mathrm{m}^{2}-900 \mathrm{~W} / \mathrm{m}^{2}-1000 \mathrm{~W} /$ $\mathrm{m}^{2}-900 \mathrm{~W} / \mathrm{m}^{2}$ are shown in Figure 8 where the PV power and the smoothing power are shown in Figure 8(a); the calculated SOC is shown in Figure 8(b). At $240 \mathrm{~s}$ of this case, the measured three-phase currents at the PV power plant emulator are shown in Figure 8(c); the measured three-phase currents at the grid side are shown in Figure 8(d); and the measured three-phase output currents of the inverter are shown in Figure 8(e). At $480 \mathrm{~s}$ of this case, the measured three-phase currents at the PV power plant emulator are 


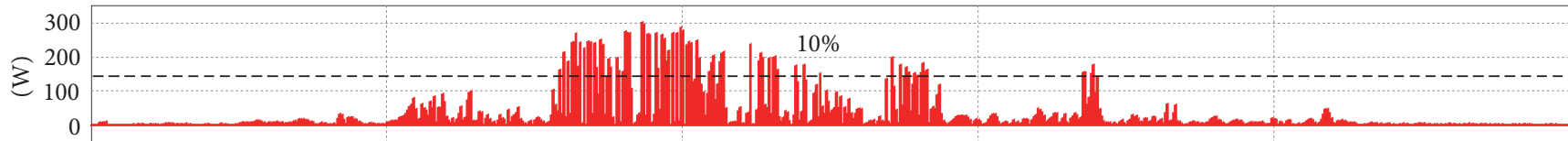

(a)

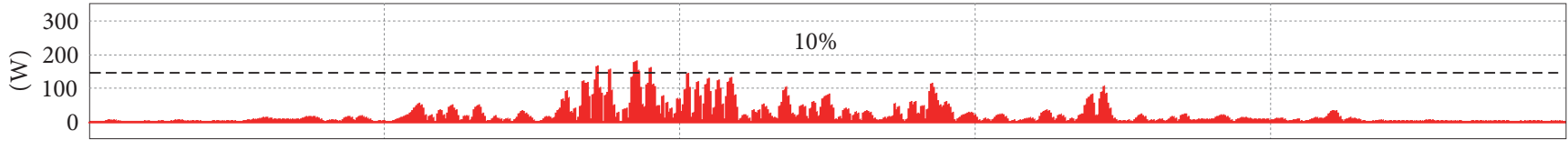

(b)

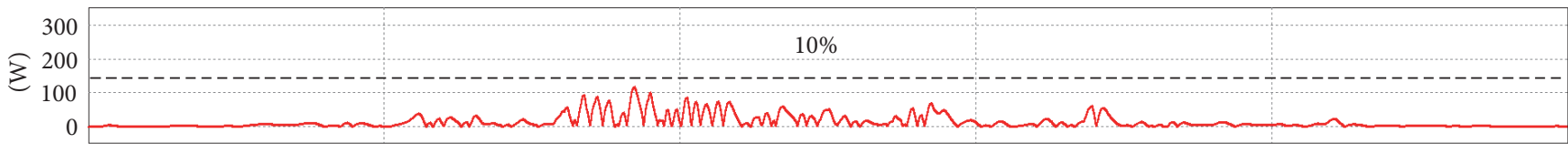

(c)

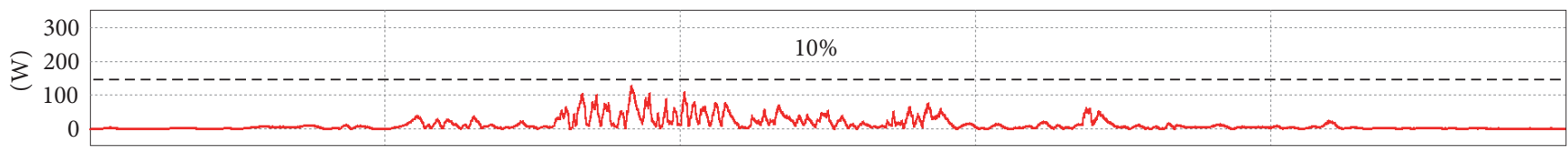

(d)
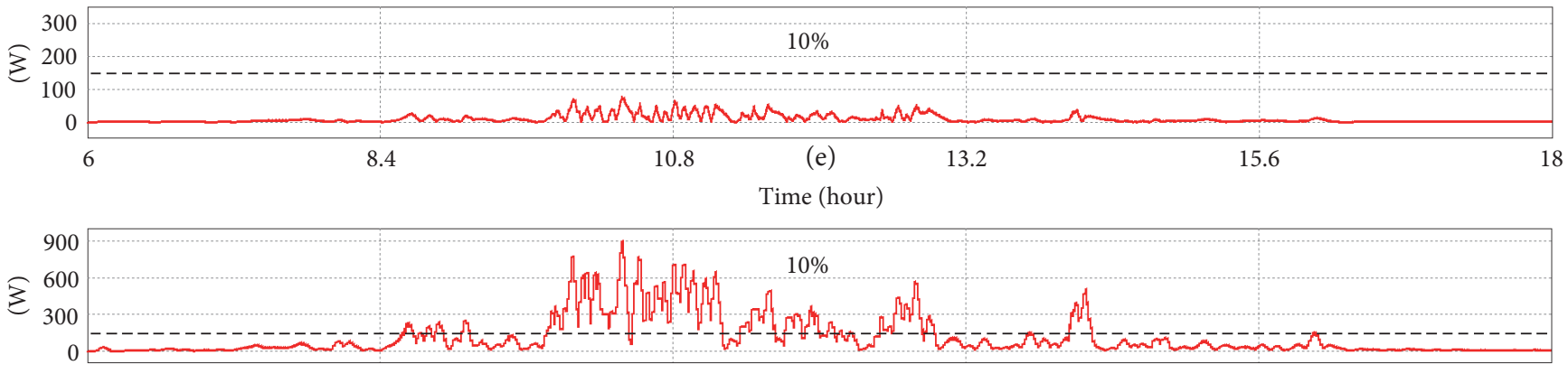

(f)

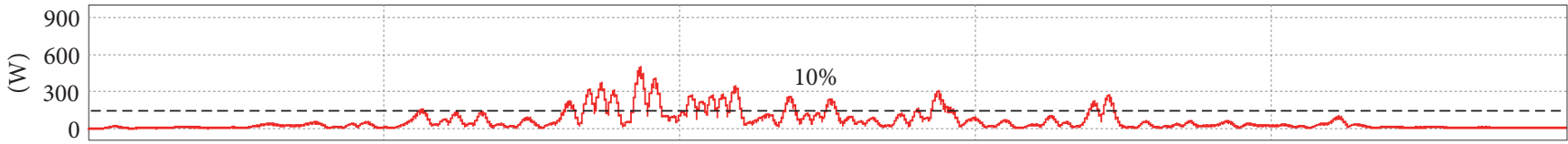

(g)

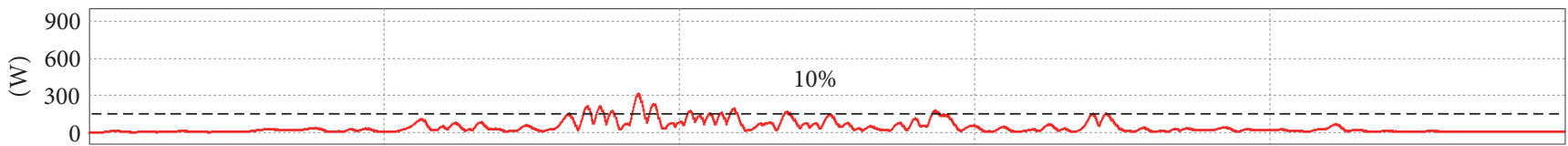

(h)

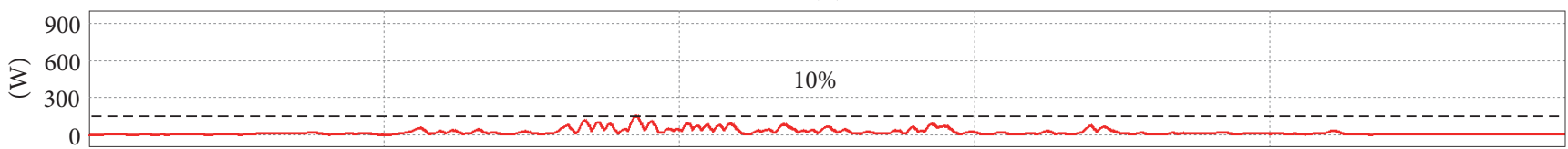

(i)

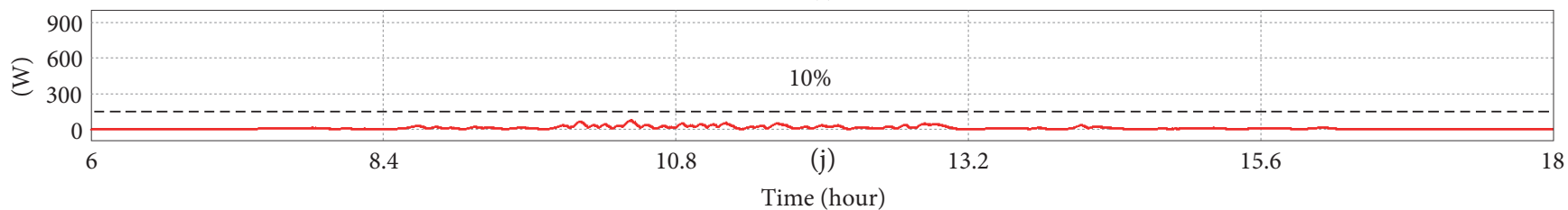

FIGURE 5: Fluctuation percentage of the injected power: (a) 1 min average window of original injected power; (b) 1 min average window of moving average method; (c) 1 min average window of low-pass filter method; (d) 1 min average window of PFNN method; (e) 1 min average window of PFNN-AMF method; (f) 10 min average window of original injected power; (g) 10 min average window of moving average method; (h) $10 \mathrm{~min}$ average window of low-pass filter method; (i) $10 \mathrm{~min}$ average window of PFNN method; (j) 10 min average window of PFNN-AMF method. 


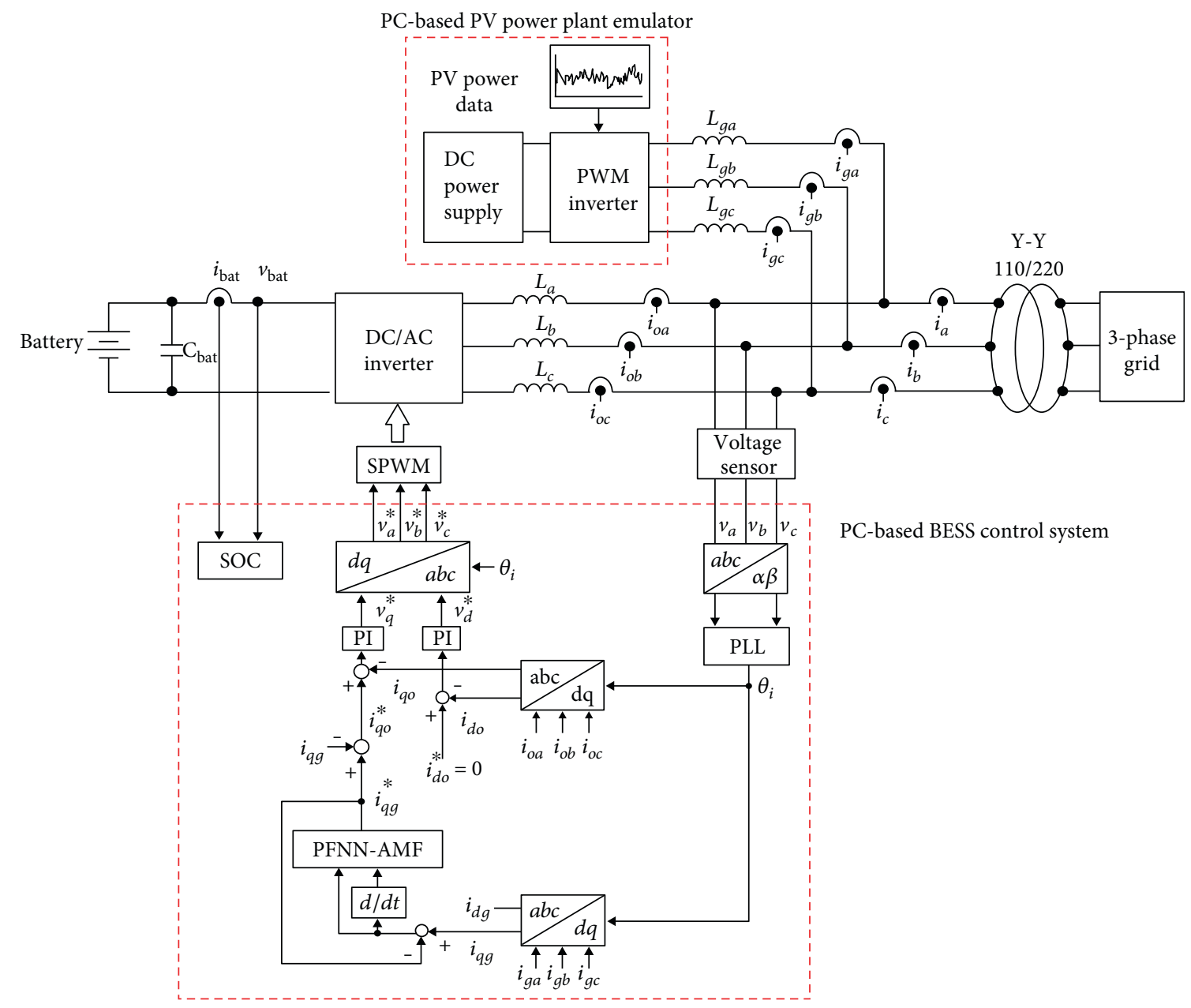

FIgURe 6: Architecture of the system.

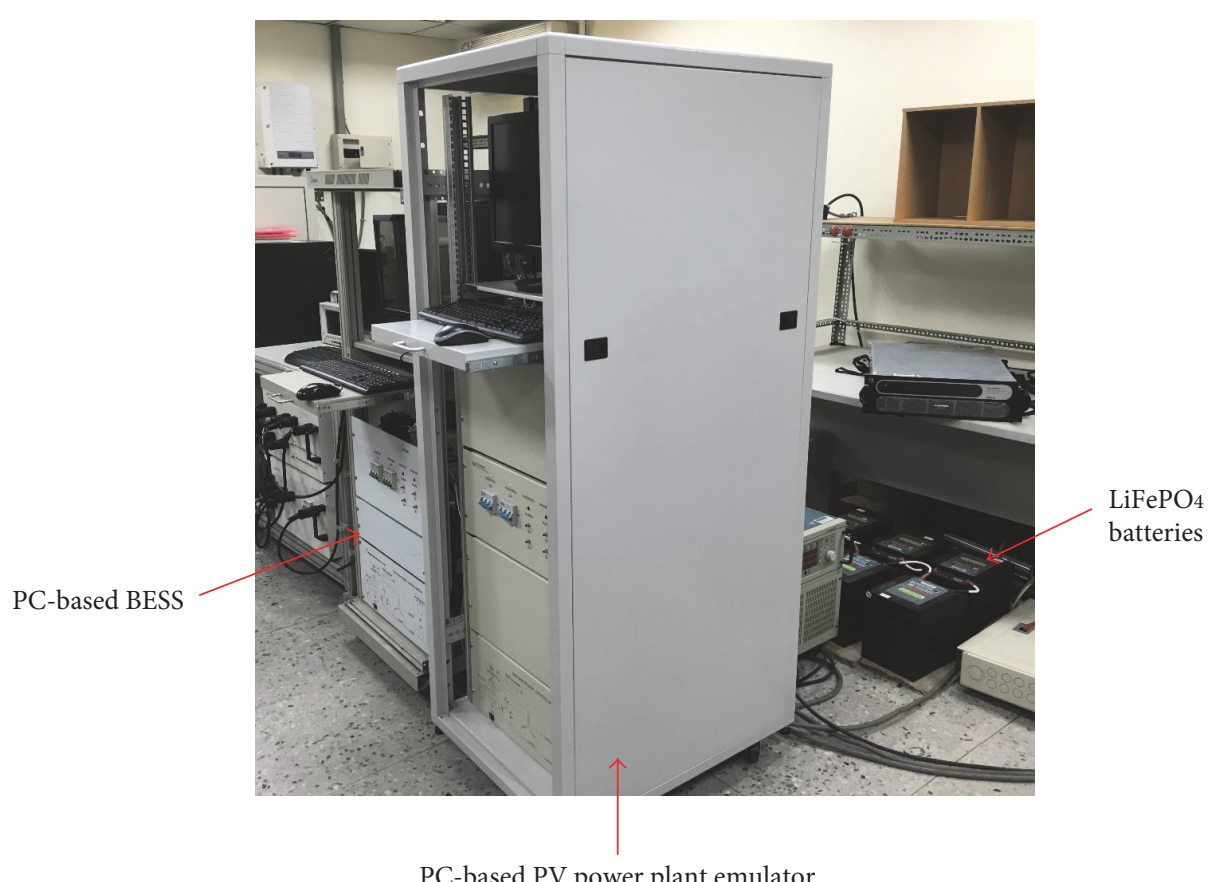

Figure 7: A photo of the experimental set-up. 


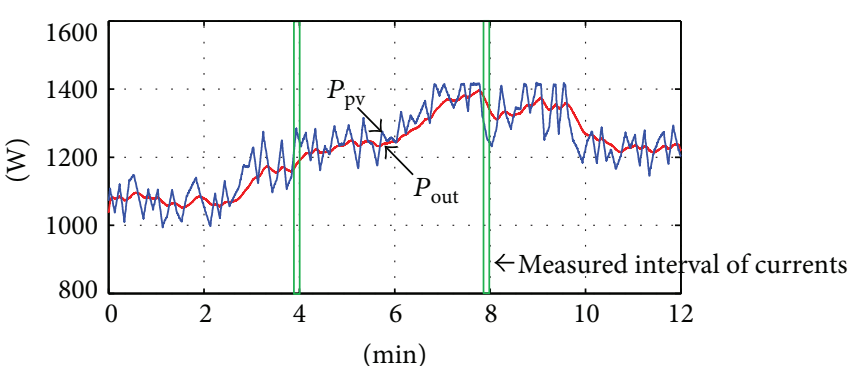

(a)

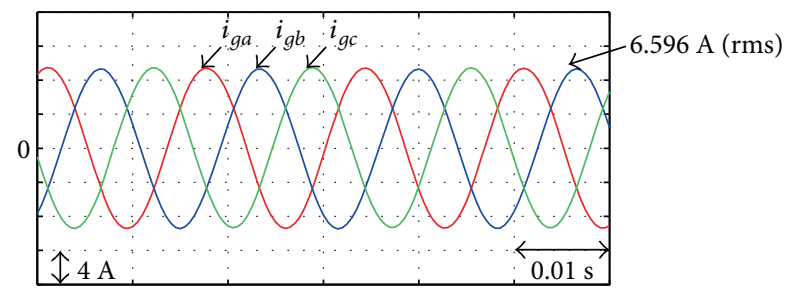

(c)

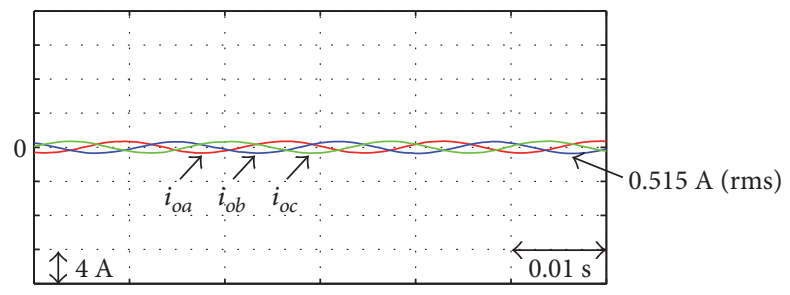

(e)

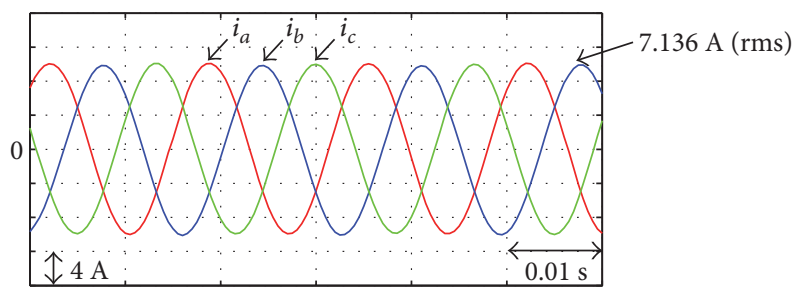

(g)

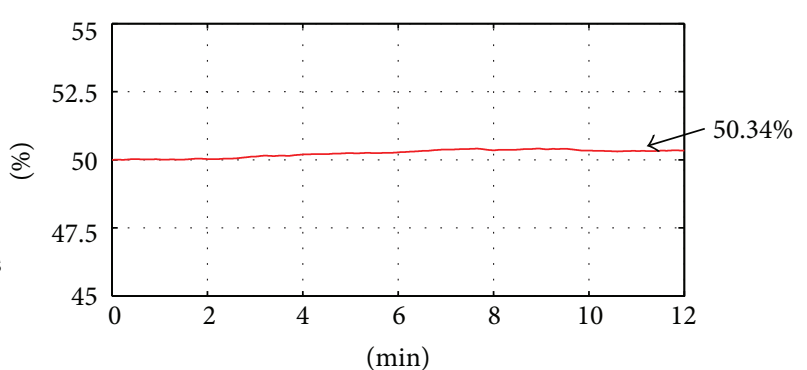

(b)

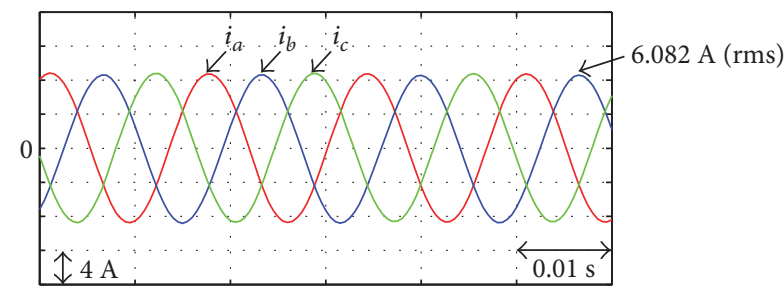

(d)

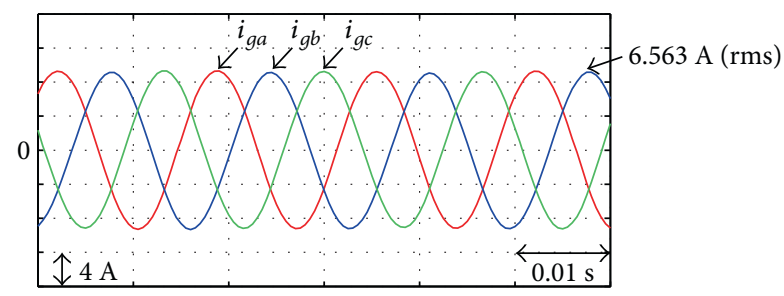

(f)

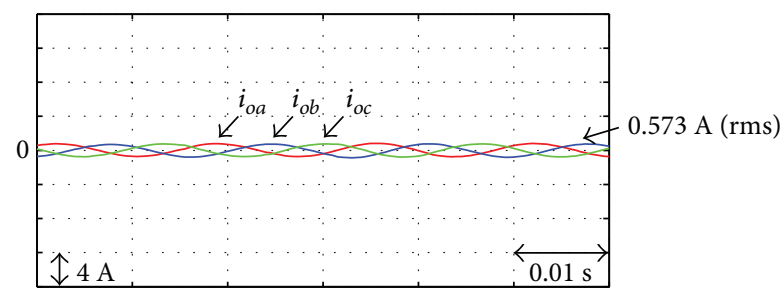

(h)

Figure 8: Experimental results using PFNN-AMF smoothing method at PV irradiance $700 \mathrm{~W} / \mathrm{m}^{2}-900 \mathrm{~W} / \mathrm{m}^{2}-1000 \mathrm{~W} / \mathrm{m}^{2}-900 \mathrm{~W} / \mathrm{m}^{2}:(\mathrm{a}) \mathrm{PV}$ power and smoothing power; (b) SOC estimation of batteries; (c) measured three-phase current at PV power plant emulator at $240 \mathrm{~s}$; (d) measured three-phase currents at grid side at $240 \mathrm{~s}$; (e) measured three-phase output currents of inverter at $240 \mathrm{~s}$; (f) measured threephase current at PV power plant emulator at $480 \mathrm{~s}$; (g) measured three-phase currents at grid side at $480 \mathrm{~s}$; (h) measured three-phase output currents of inverter at $480 \mathrm{~s}$.

shown in Figure 8(f); the measured three-phase currents at the grid side are shown in Figure $8(\mathrm{~g})$; and the measured three-phase output currents of the inverter are shown in Figure $8(\mathrm{~h})$. Moreover, the experimental results using the proposed PFNN-AMF smoothing method at the PV irradiance variation condition $900 \mathrm{~W} / \mathrm{m}^{2}-1000 \mathrm{~W} / \mathrm{m}^{2}-900 \mathrm{~W} /$ $\mathrm{m}^{2}-800 \mathrm{~W} / \mathrm{m}^{2}$ are shown in Figure 9 where the PV power and the smoothing power are shown in Figure 9(a); the calculated SOC is shown in Figure 9(b). At $120 \mathrm{~s}$ of this case, the measured three-phase currents at the PV power plant emulator are shown in Figure 9(c); the measured three-phase currents at the grid side are shown in Figure 9(d); and the measured three-phase output currents of the inverter are shown in Figure 9(e). At $280 \mathrm{~s}$ of this case, the measured three-phase currents at the PV power plant emulator are shown in Figure 9(f); the measured three-phase currents at the grid side are shown in Figure $9(\mathrm{~g})$; and the measured three-phase output currents of the inverter are shown in Figure 9(h). Furthermore, the experimental results using the proposed PFNN-AMF smoothing method at the PV irradiance variation condition $700 \mathrm{~W} / \mathrm{m}^{2}-800 \mathrm{~W} / \mathrm{m}^{2}-700 \mathrm{~W} /$ $\mathrm{m}^{2}-900 \mathrm{~W} / \mathrm{m}^{2}-1000 \mathrm{~W} / \mathrm{m}^{2}$ are shown in Figure 10 where the $\mathrm{PV}$ power and the smoothing power are shown in Figure 10(a); the calculated SOC is shown in Figure 10(b). At $270 \mathrm{~s}$ of this case, the measured three-phase currents at the PV power plant emulator are shown in Figure 10(c); the measured three-phase currents at the grid side are shown in Figure 10(d); and the measured three-phase output currents of the inverter are shown in Figure 10(e). At $480 \mathrm{~s}$ of this case, the measured three-phase currents at the PV power plant 


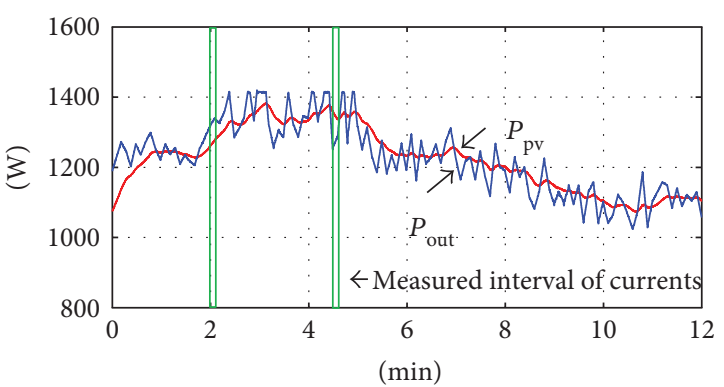

(a)

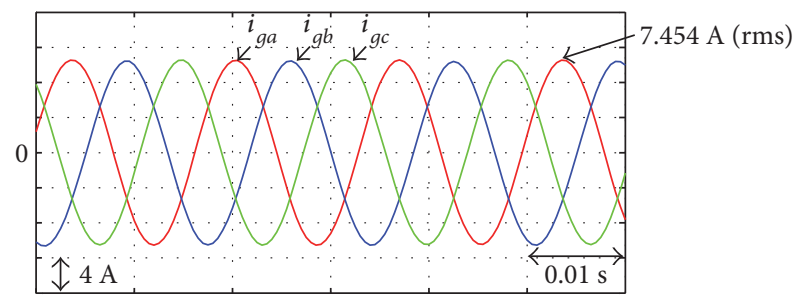

(c)

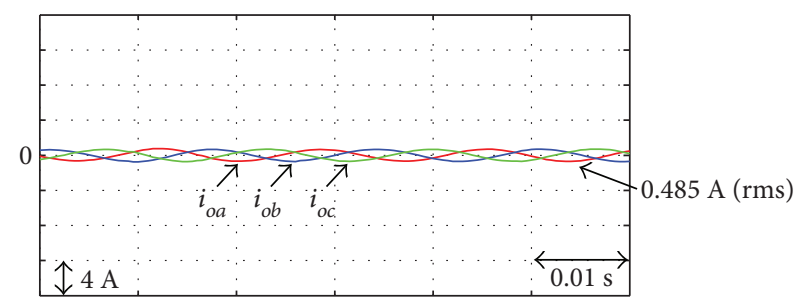

(e)

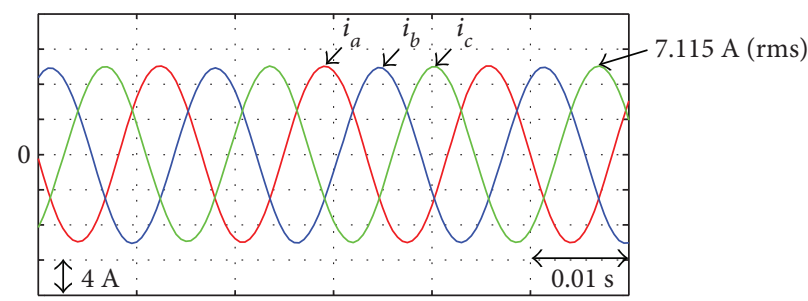

(g)

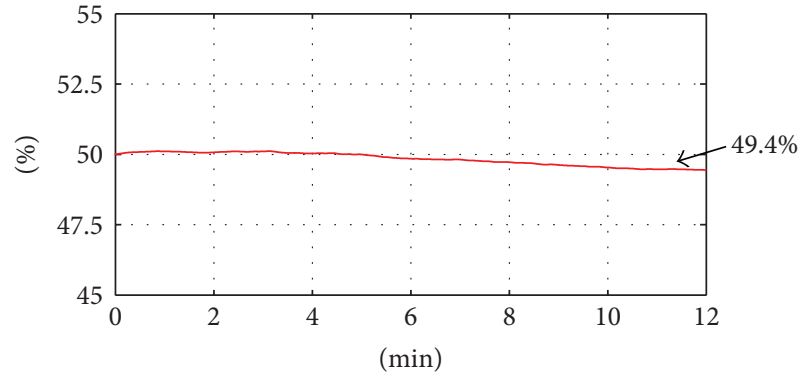

(b)

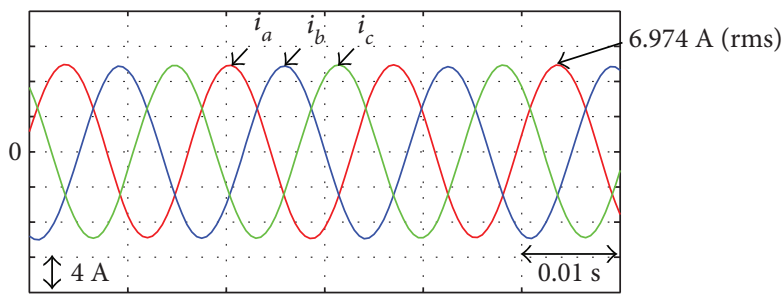

(d)

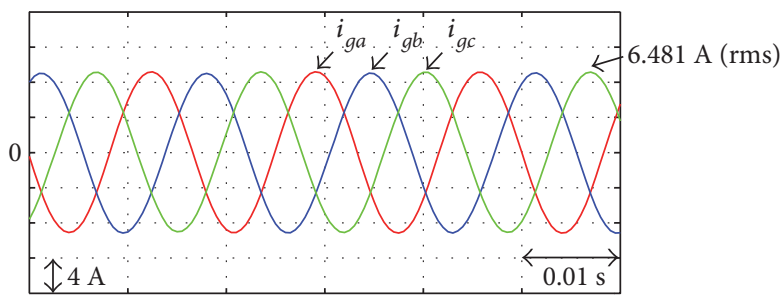

(f)

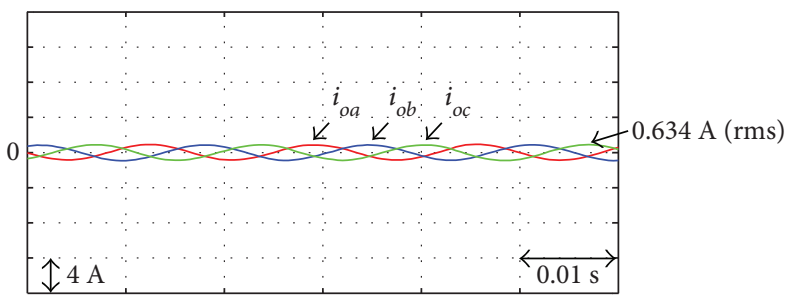

(h)

FIGURE 9: Experimental results using PFNN-AMF smoothing method at PV irradiance $900 \mathrm{~W} / \mathrm{m}^{2}-1000 \mathrm{~W} / \mathrm{m}^{2}-900 \mathrm{~W} / \mathrm{m}^{2}-800 \mathrm{~W} / \mathrm{m}^{2}:(\mathrm{a}) \mathrm{PV}$ power and smoothing power; (b) SOC estimation of batteries; (c) measured three-phase current at PV power plant emulator at $120 \mathrm{~s}$; (d) measured three-phase currents at grid side at $120 \mathrm{~s}$; (e) measured three-phase output currents of inverter at $120 \mathrm{~s}$; (f) measured threephase current at PV power plant emulator at $280 \mathrm{~s}$; (g) measured three-phase currents at grid side at $280 \mathrm{~s}$; (h) measured three-phase output currents of inverter at $280 \mathrm{~s}$.

emulator are shown in Figure 10(f); the measured threephase currents at the grid side are shown in Figure 10(g); and the measured three-phase output currents of the inverter are shown in Figure 10(h). From the experimental results shown in Figures 8(a) and 8(b), Figures 9(a) and 9(b), and Figures 10(a) and 10(b), the effectiveness of the proposed intelligent PV power smoothing control is obvious. Moreover, the fluctuation of injected power to the grid is kept below $10 \%$ of the rated power for both per minute and per ten minutes to maintain the grid power quality at all test conditions. In order to observe the charge phenomena of the $\mathrm{LiFePO}_{4}$ battery, all the measured currents for $0.06 \mathrm{~s}$ period of time are shown in Figures 8(c), 8(d), and 8(e), Figures 9(c), 9(d), and 9(e), and Figures 10(f), 10(g), and 10(h). On the other hand, in order to observe the discharge phenomena of the $\mathrm{LiFePO}_{4}$ battery, all the measured currents for $0.06 \mathrm{~s}$ period of time are shown in Figures $8(\mathrm{f}), 8(\mathrm{~g})$, and 8(h), Figures 9(f), 9(g), and 9(h), and Figures 10(c), 10(d), and $10(\mathrm{e})$. As a result, it can verify that the difference of the actual PV power and the smoothed power is supplied by the BESS effectively at all test conditions.

\section{Conclusions}

An intelligent PV power smoothing control using PFNNAMF has been successfully developed in this study. By using the excellent approximation and online training abilities of the proposed PFNN-AMF smoothing method, a smoothed 


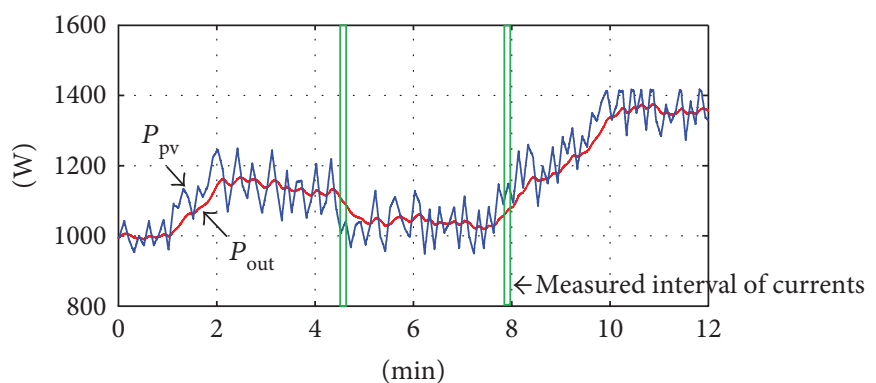

(a)

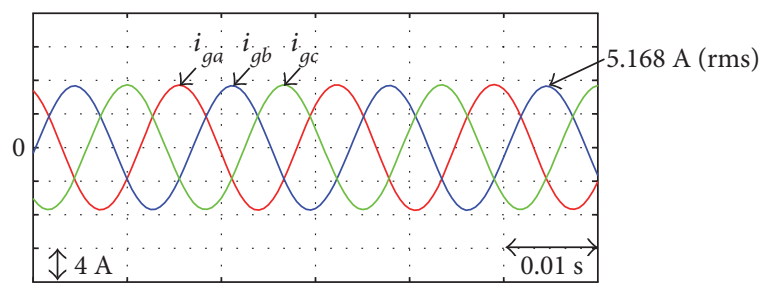

(c)

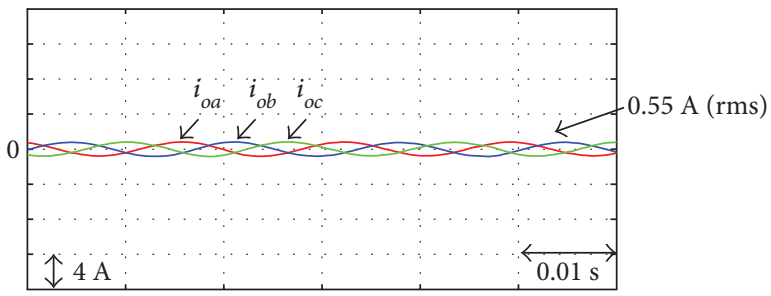

(e)

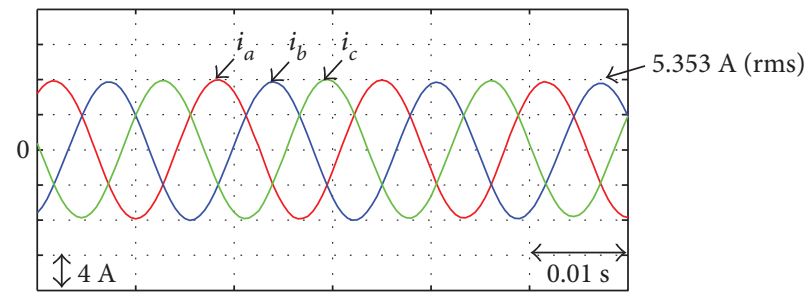

(g)

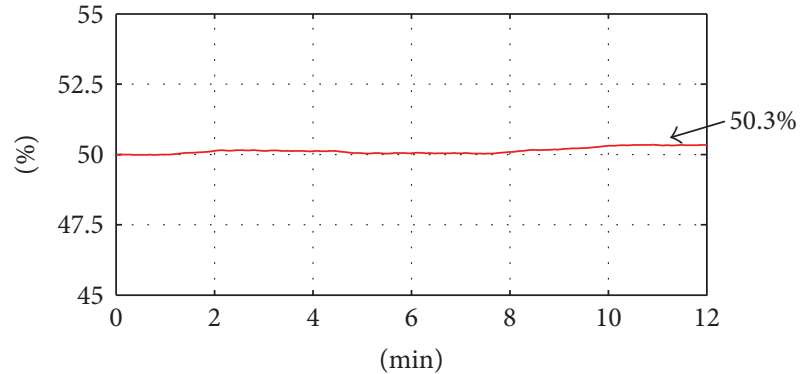

(b)

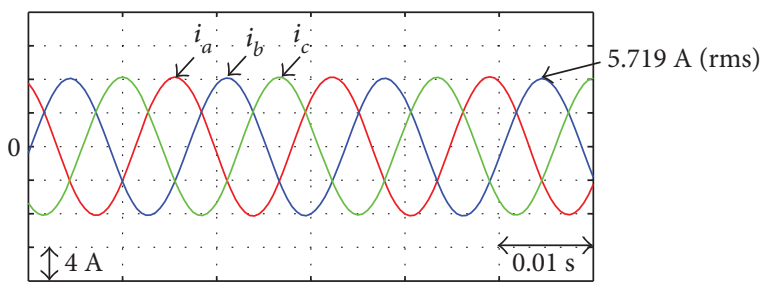

(d)

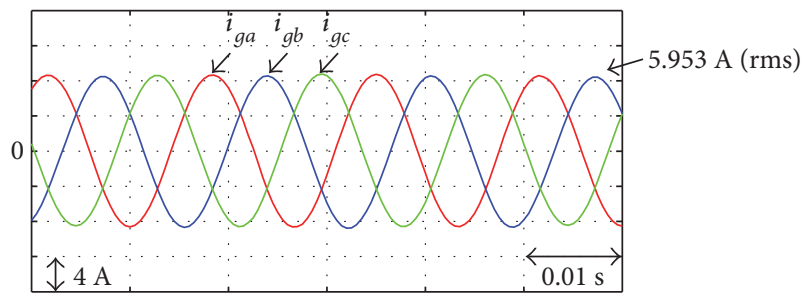

(f)

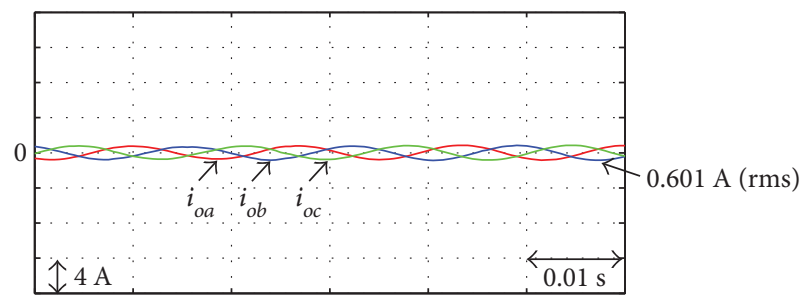

(h)

Figure 10: Experimental results using PFNN-AMF smoothing method at PV irradiance $700 \mathrm{~W} / \mathrm{m}^{2}-800 \mathrm{~W} / \mathrm{m}^{2}-700 \mathrm{~W} / \mathrm{m}^{2}-900 \mathrm{~W} / \mathrm{m}^{2}-$ $1000 \mathrm{~W} / \mathrm{m}^{2}$ : (a) PV power and smoothing power; (b) SOC estimation of batteries; (c) measured three-phase current at PV power plant emulator at $270 \mathrm{~s}$; (d) measured three-phase currents at grid side at $270 \mathrm{~s}$; (e) measured three-phase output currents of inverter at $270 \mathrm{~s}$; (f) measured three-phase current at PV power plant emulator at $480 \mathrm{~s}$; (g) measured three-phase currents at grid side at $480 \mathrm{~s}$; (h) measured three-phase output currents of inverter at $480 \mathrm{~s}$.

power curve with limited time delay has been obtained. Moreover, the difference of the actual PV power and smoothed power is supplied by the BESS. Comparing to the other smoothing methods, a minimum energy capacity of the BESS has been achieved using the proposed PFNNAMF power smoothing control. From the experimental results of various PV irradiance variation conditions, the effectiveness of the proposed intelligent PV power smoothing control has been verified. The major contributions of this study are (1) the design of a single-stage and gridconnected BESS using bidirectional DC/AC 3-phase inverter and LiFePO4 batteries; (2) the development of the proposed PFNN-AMF and its online learning algorithm; (3) the development of an intelligent PV power smoothing control using PFNN-AMF; and (4) the achievement of the minimum energy and power capacities of the battery and a small fluctuation of the grid active power by using the PFNN-AMF PV power smoothing control.

\section{Conflicts of Interest}

The authors declare that there is no conflict of interests regarding the publication of this paper.

\section{Acknowledgments}

The authors would like to acknowledge the financial support from the Ministry of Science and Technology of Taiwan through its Grant MOST 104-2221-E-008-041-MY3. 


\section{References}

[1] EPIA, Global Market Outlook for Solar Power 2015-2019, 2016.

[2] F. J. Lin, K. C. Lu, T. H. Ke, B. H. Yang, and Y. R. Chang, "Reactive power control of three-phase grid-connected PV system during grid faults using Takagi-Sugeno-Kang probabilistic," IEEE Transactions on Industry Electronics, vol. 62, no. 9, pp. 5516-5528, 2015.

[3] G. Wang, G. Konstantinou, C. D. Townsend et al., "A review of power electronics for grid connection of utility-scale battery energy storage systems," IEEE Transactions on Sustainable Energy, vol. 7, no. 4, pp. 1778-1790, 2016.

[4] G. Wang, M. Ciobotaru, and V. G. Agelidis, "Power smoothing of large solar PV plant using hybrid energy storage," IEEE Transactions on Sustainable Energy, vol. 5, no. 3, pp. 834842, 2014.

[5] X. Li, D. Hui, and X. Lai, "Battery energy storage station (BESS)-based smoothing control of photovoltaic (PV) and wind power generation fluctuations," IEEE Transactions on Sustainable Energy, vol. 4, no. 2, pp. 464-473, 2013.

[6] A. Saez-de-Ibarra, E. Martinez-Laserna, D. Stroe, M. Swierczynski, and P. Rodriguez, "Sizing study of second life li-ion batteries for enhancing renewable energy grid integration," IEEE Transactions on Industry Applications, vol. 52, no. 6, pp. 4999-5008, 2016.

[7] F. J. Lin, H. C. Chiang, J. K. Chang, and Y. R. Chang, "Intelligent wind power smoothing control with BESS," IET Renewable Power Generation, vol. 11, no. 2, pp. 398-407, 2017.

[8] W. Y. Chang, "The state of charge estimating methods for battery: a review," ISRN Applied Mathematics, vol. 2013, Article ID 953792, 7 pages, 2013.

[9] C. Zhang, L. Y. Wang, X. Li, W. Chen, G. G. Yin, and J. Jiang, "Robust and adaptive estimation of state of charge for lithiumion batteries," IEEE Transactions on Industry Electronics, vol. 62, no. 8, pp. 4948-4957, 2015.

[10] G. Dong, J. Wei, C. Zhang, and Z. Chen, "Online state of charge estimation and open circuit voltage hysteresis modeling of LiFePO4 battery using invariant imbedding method," Applied Energy, vol. 162, pp. 163-171, 2016.

[11] Z. Liu, D. W. Gao, Y. H. Wan, and E. Muljadi, "Wind power plant prediction by using neural networks," in 2012 IEEE Energy Conversion Congress and Exposition (ECCE), pp. 3154-3160, Raleigh, NC, USA, September 2012.

[12] F. J. Lin, K. H. Tan, and C. H. Tsai, "Improved differential evolution-based Elman neural network controller for squirrel-cage induction generator system," IET Renewable Power Generation, vol. 10, no. 7, pp. 988-1001, 2016.

[13] M. E. G. Urias, E. N. Sanchez, and L. J. Ricalde, "Electrical microgrid optimization via a new recurrent neural network," IEEE System Journal, vol. 9, no. 3, pp. 945-953, 2015.

[14] W. Yu and X. Li, "Fuzzy identification using fuzzy neural networks with stable learning algorithms," IEEE Transactions on Fuzzy Systems, vol. 12, no. 3, pp. 411-420, 2004.

[15] F. J. Lin, P. K. Huang, and C. C. Wang, "An induction generator system using fuzzy modeling and recurrent fuzzy neural network," IEEE Transactions on Power Electronics, vol. 22, no. 1, pp. 260-271, 2007.

[16] D. F. Specht, "Probabilistic neural network," Neural Networks, vol. 3, no. 1, pp. 109-118, 1990.
[17] K. Z. Mao, K. C. Tan, and W. Ser, "Probabilistic neuralnetwork structure determination for pattern classification," IEEE Transactions on Neural Networks, vol. 11, no. 4, pp. 1009-1016, 2000.

[18] J. C. Pidre, C. J. Carrillo, and A. E. F. Lorenzo, "Probabilistic model for mechanical power fluctuations in asynchronous wind parks," IEEE Transactions on Power Systems, vol. 18, no. 2, pp. 761-768, 2003.

[19] M. Tripathy, R. P. Maheshwari, and H. K. Verma, "Power transformer differential protection based on optimal probabilistic neural network," IEEE Transactions on Power Delivery, vol. 25, no. 1, pp. 102-112, 2010.

[20] F. J. Lin, M. S. Huang, P. Y. Yeh, H. C. Tsai, and C. H. Kuan, "DSP-based probabilistic fuzzy neural network control for liion battery charger," IEEE Transactions on Power Electronics, vol. 27, no. 8, pp. 3782-3794, 2012.

[21] F. J. Lin, Y. C. Hung, J. C. Hwang, I. P. Chang, and M. T. Tsai, "Digital signal processor-based probabilistic fuzzy neural network control of in-wheel motor drive for light electric vehicle," IET Electric Power Applications, vol. 6, no. 2, pp. 47-61, 2012.

[22] K. H. Cheng, C. F. Hsu, C. M. Lin, T. T. Lee, and C. Li, "Fuzzy neural sliding mode control for dc-dc converters using asymmetric gaussian membership functions," IEEE Transactions on Industry Electronics, vol. 54, no. 3, pp. 1528-1536, 2004.

[23] C. H. Lee, T. W. Hu, C. T. Lee, and Y. C. Lee, "A recurrent interval type-2 fuzzy neural network with asymmetric membership functions for nonlinear system identification," in Proceeding of the IEEE International Conference on Fuzzy System, pp. 1496-1502, Hong Kong, China, September 2008.

[24] D. K. Khatod, V. Pant, and J. Sharma, “Analytical approach for wellbeing assessment of small autonomous power systems with solar and wind energy sources," IEEE Transactions on Energy Conversion, vol. 25, no. 2, pp. 535-545, 2010.

[25] I. Parra, M. Muñoz, E. Lorenzo, M. García, J. Marcos, and F. Martínez-Moreno, "PV performance modelling: a review in the light of quality assurance for large PV plants," Renewable and Sustainable Energy Reviews, vol. 78, pp. 780-797, 2017.

[26] IEC 61724, Photovoltaic System Performance Monitoring Guidelines for Measurement, Data Exchange and Analysis, 1998.

[27] F. J. Lin, P. H. Chou, Y. C. Hung, and W. M. Wang, "Fieldprogrammable gate array-based functional link radial basis function network control for permanent magnet linear synchronous motor servo drive system," IET Electric Power Applications, vol. 4, no. 5, pp. 357-372, 2010.

[28] The University of Queensland, "UQ SOLAR photovoltaic live data," March 2013, http://solar.uq.edu.au/user/report Power.php.

[29] M. Jannati, S. H. Hosseinian, B. Vahidi, and G. J. Li, "Mitigation of windfarm power fluctuation by adaptive linear neuron-based power tracking method with flexible learning rate," IET Renewable Power Generation, vol. 8, no. 6, pp. 659-669, 2014. 

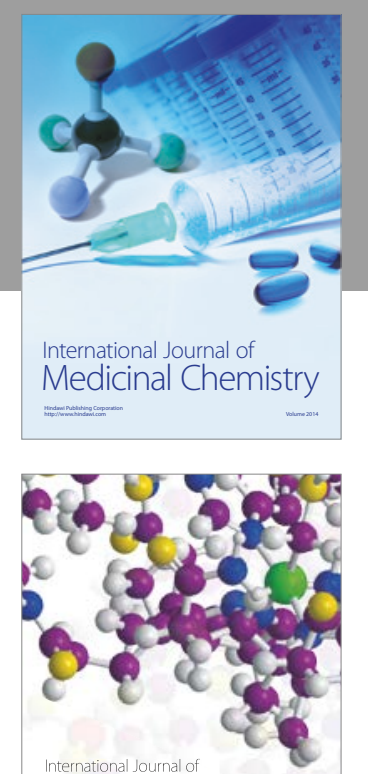

Carbohydrate Chemistry

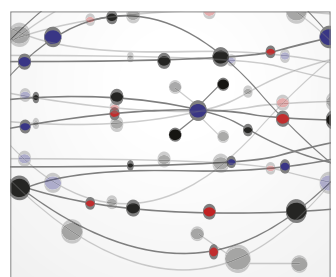

The Scientific World Journal
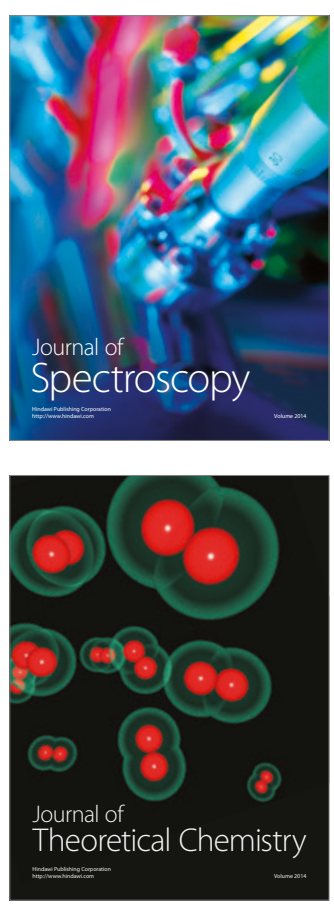
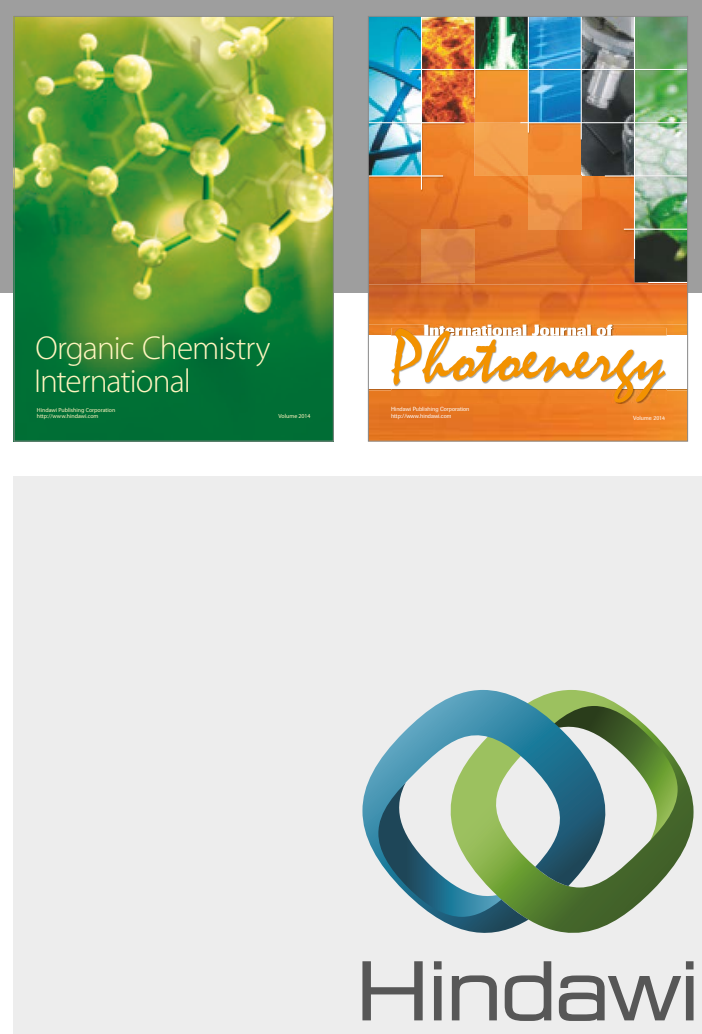

Submit your manuscripts at

https://www.hindawi.com

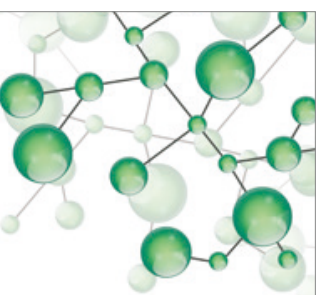

International Journal of

Inorganic Chemistry

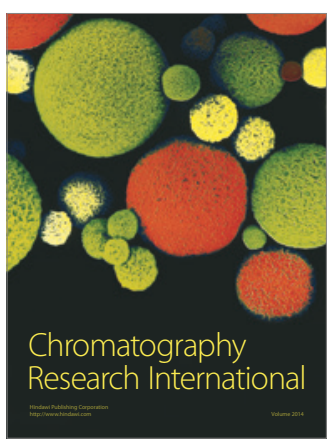

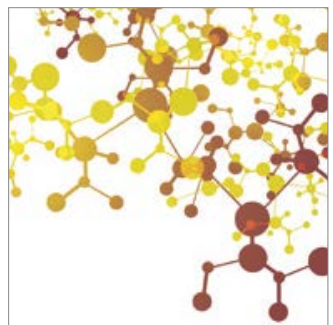

Applied Chemistry
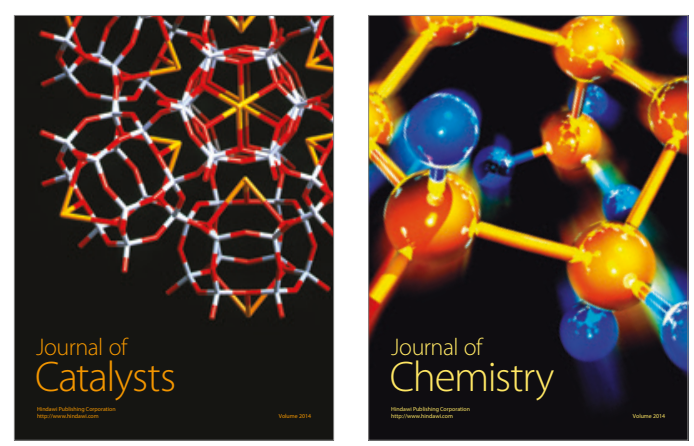
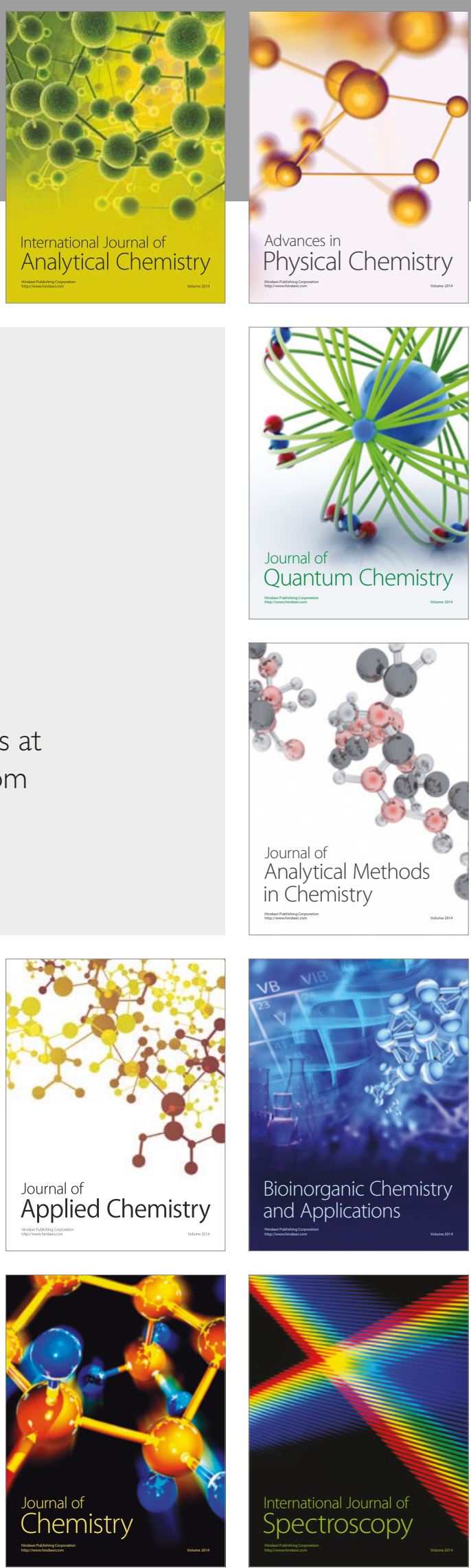